ANL-6024

Reactors - General

(TID-4500, 15th Ed.)

AEC Research and

Development Report

ARGONNE NATIONAL LABORATORY

P. O. Box 299

Lemont, Illinois

\title{
DESIGN AND HAZARDS REPORT \\ FOR THE \\ ARGONNE FAST SOURCE REACTOR (AFSR) \\ by
}

G. S. Brunson

Idaho Division

\section{Contributors}

R. N. Curran

R. O. Haroldsen

D. C. Jacobson

F. S. Kirn

R. L. McVean

R. E. Rice

F. W. Thalgott

M. B. Trillhaase

June, 1959

Operated by The University of Chicago under, '

Contract $W-31=$ eng- 38 


\section{DISCLAIMER}

This report was prepared as an account of work sponsored by an agency of the United States Government. Neither the United States Government nor any agency Thereof, nor any of their employees, makes any warranty, express or implied, or assumes any legal liability or responsibility for the accuracy, completeness, or usefulness of any information, apparatus, product, or process disclosed, or represents that its use would not infringe privately owned rights. Reference herein to any specific commercial product, process, or service by trade name, trademark, manufacturer, or otherwise does not necessarily constitute or imply its endorsement, recommendation, or favoring by the United States Government or any agency thereof. The views and opinions of authors expressed herein do not necessarily state or reflect those of the United States Government or any agency thereof. 


\section{DISCLAIMER}

Portions of this document may be illegible in electronic image products. Images are produced from the best available original document. 


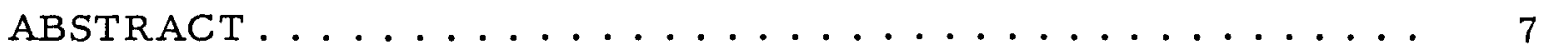

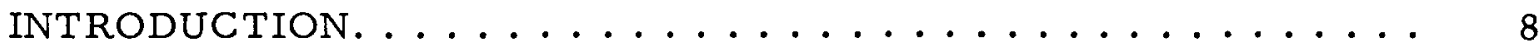

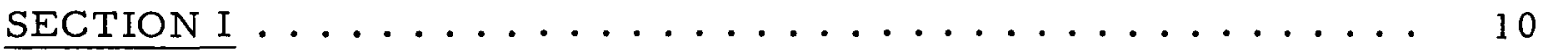

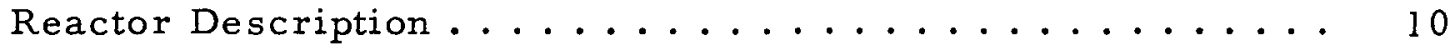

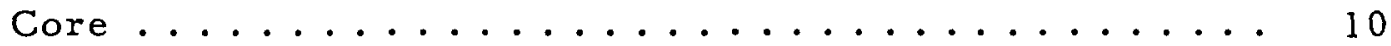

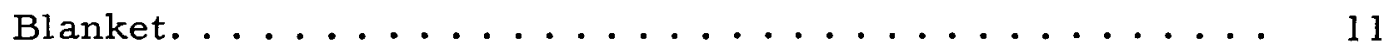

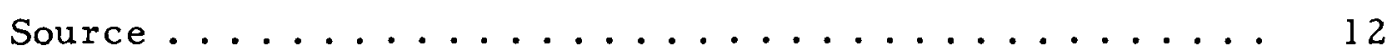

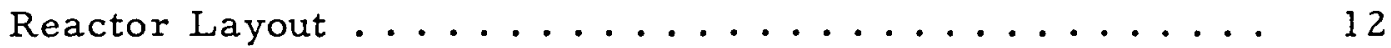

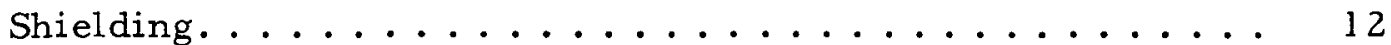

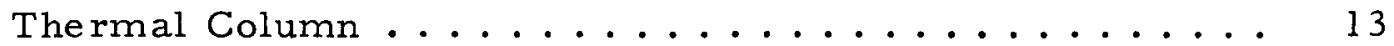

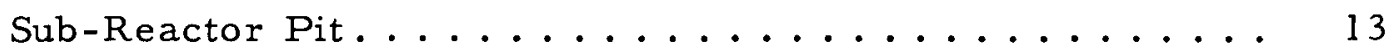

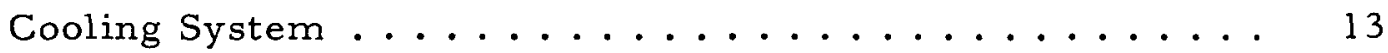

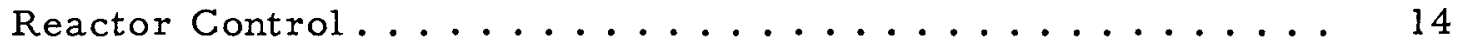

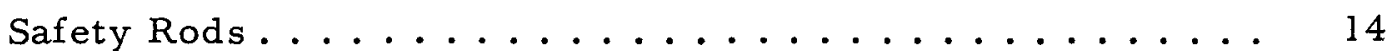

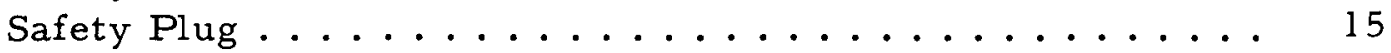

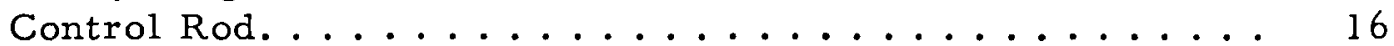

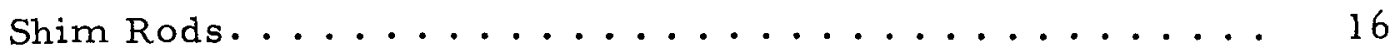

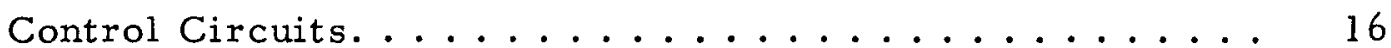

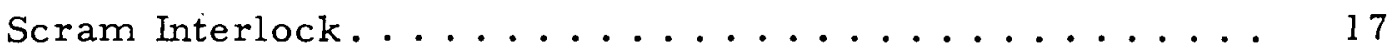

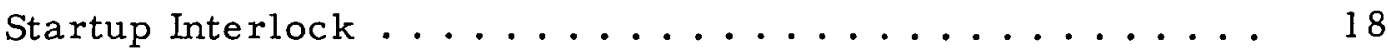

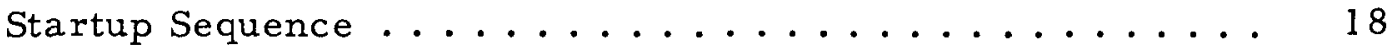

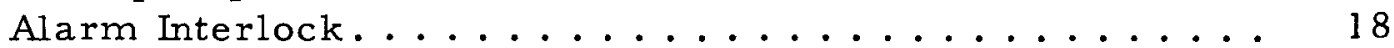

Reactor Instrumentation ................... I 8

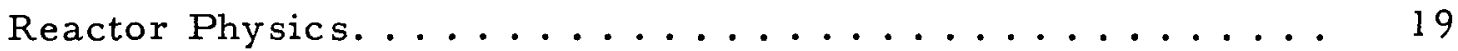

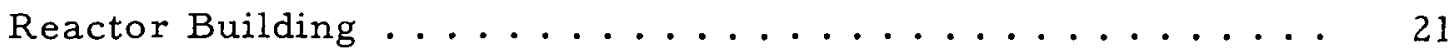

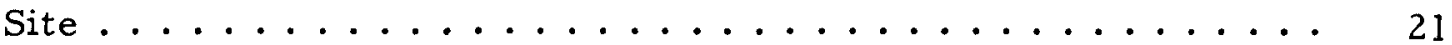

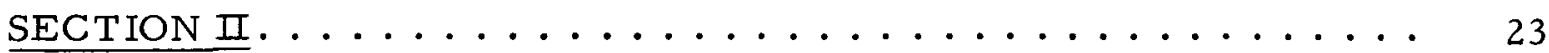

Management of the Reactor ................... 23

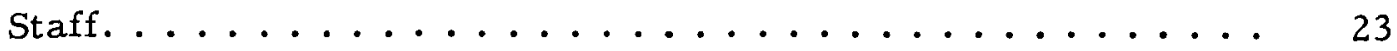

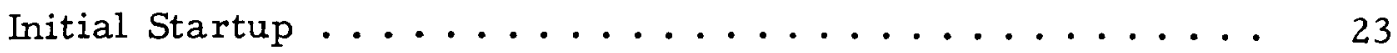

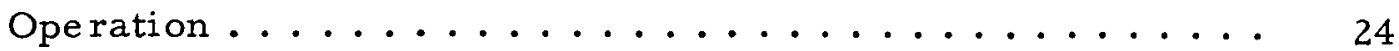




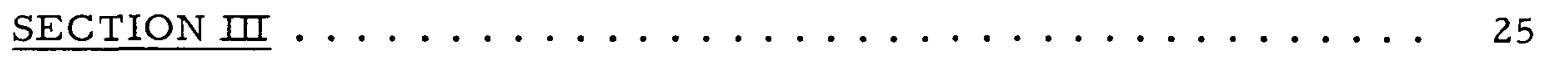

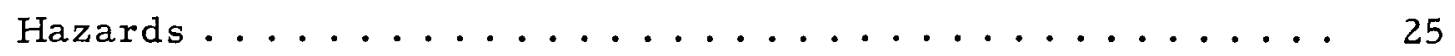

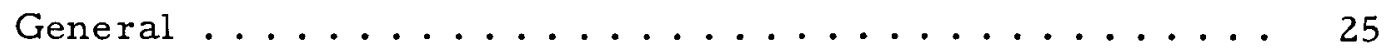

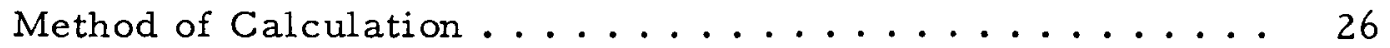

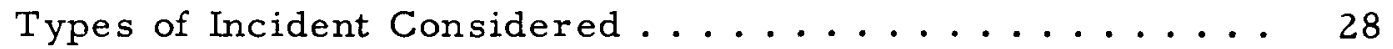

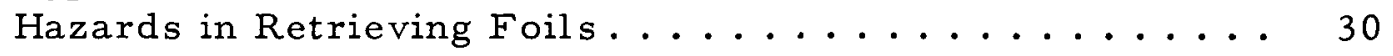

Miscellaneous Hazards ................ 30

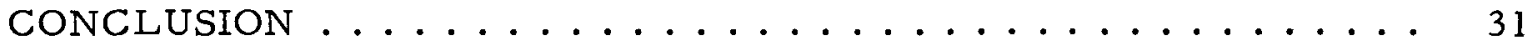

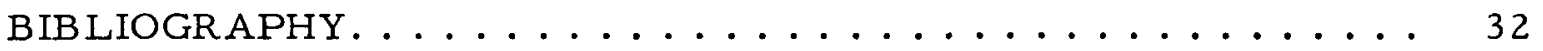

APPENDIX I LOADING ERROR WITH MACHINE FAILURE . . . . 33

APPENDIX $\Pi$ ERROR OR MISHAP IN OPERATION . . . . . . . . 39 
LIST OF FIGURES

No.

Title

$\underline{\text { Page }}$

1 Core Assembly ...................... 41

2 Blanket and Core Assemblies................ 42

3 Cutaway View of Argonne Fast Source Reactor. . . . . . . . 43

4 Reactor and Thermal Column . . . . . . . . . . . . 44

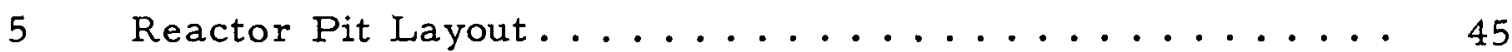

6 Safety Rod Drive Assembly .................. 46

7 Safety Rod Performance Curve............... 47

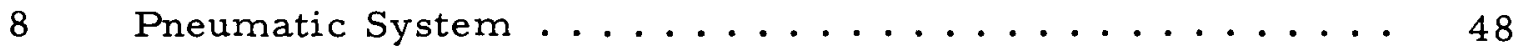

8 a Safety Plug Performance Curve .............. 49

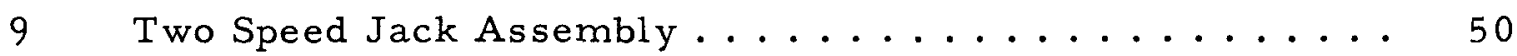

10 Control Rod Drive Assembly ................ 51

11 Shim Rod Actuator Assembly ............... 52

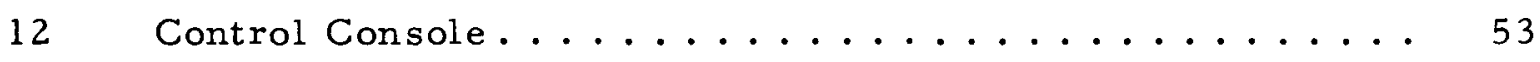

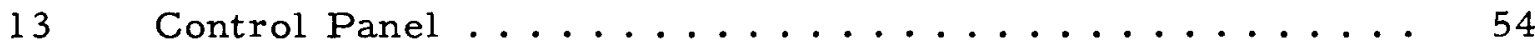

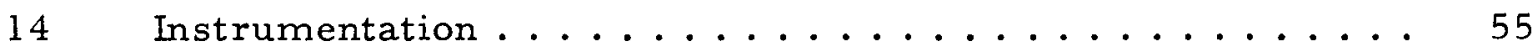

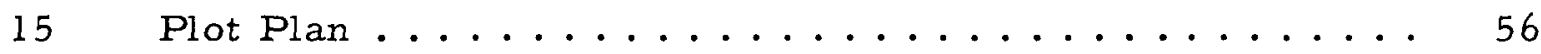

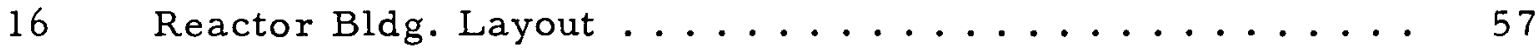

17 National Reactor Testing Station Map. ........... 58

18 Central Facilities 20 Foot Level Wind Rose 1950

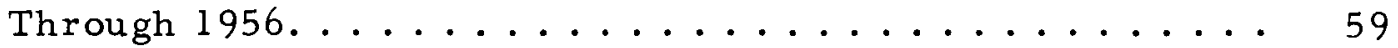

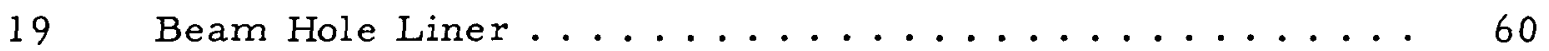

20 Predicted Behavior of AFSR Going Critical 0.1 inch from Fully Assembled Position at a Rate of $0.0004 \Delta \mathrm{k} / \mathrm{k}$

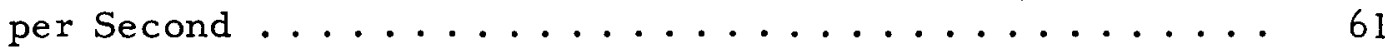

21 Predicted Behavior of AFSR Going Critical 0.3 inch from Fully Assembled Position at a Rate of $0.0004 \Delta \mathrm{k} / \mathrm{k}$

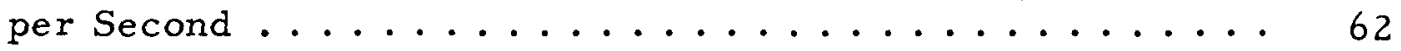

22 Predicted Behavior of AFSR Going Critical 0.1 inch from Fully Assembled Position at a Rate of $0.003 \Delta \mathrm{k} / \mathrm{k}$

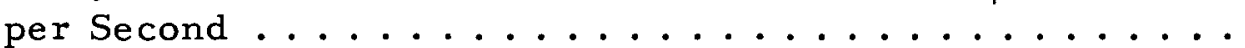




\section{LIST OF FIGURES}

No.

23 Predicted Behavior of AFSR Going Critical 0.3 inch from Fully Assembled Position at a Rate of $0.003 \Delta \mathrm{k} / \mathrm{k}$

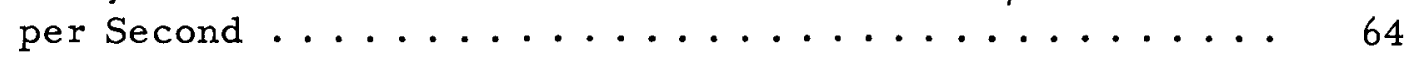

24 Predicted Behavior of AFSR Going Critical l inch from Fully Assembled Position at a Rate of $0.03 \Delta \mathrm{k} / \mathrm{k}$

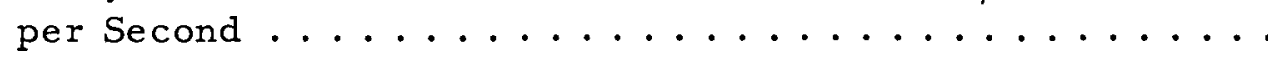

\section{LIST OF TABLES}

No.

Title

Page

I Summary of Design Characteristics ............ 9

II Reactivity Effects.................... 20

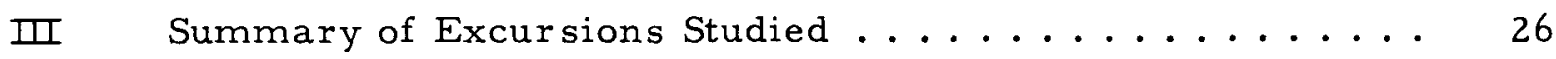

IV Probable Maximum Doses from Radiation Cloud ....... 38 
$\bullet$ 


\section{DESIGN AND HAZARDS REPORT \\ FOR THE \\ ARGONNE FAST SOURCE REACTOR (AFSR)}

G. S. Brunson

\section{ABSTRACT}

The Argonne Fast Source Reactor is designed to operate at low power (nominally 1000 watts) to supply neutron fluxes, both fast and thermal, for laboratory experiments. It is built around a cylindrical core (with vertical axis) of solid, highly enriched uranium approximately $4 \frac{1}{2}$ inches in diameter by $4 \frac{1}{4}$ inches high. The blanket is of solid depleted uranium with a minimum thickness of eight inches; its outer form is cylindrical, $20 \frac{5}{8}$ inches in diameter by $20 \frac{5}{8}$ inches high. The reactor, contained in a shield of high density concrete of minimum thickess $4 \frac{1}{2}$ feet, is freestanding on the floor of the reactor building. A graphite thermal column $4 \times 4 \times 6$ feet is provided. All control and safety mechanisms are located in a pit beneath the reactor.

The hazards associated with operation of the reactor have been analyzed. A number of potentially dange rous circumstances were studied to determine the probable severity of the resultant excursions. As an upper limit, a detailed study was made of the extreme case in which the reactor, overloaded by five kilograms of $\mathrm{U}^{235}$, goes critical at the air cylinder speed of 18 inches per minute. It is estimated that the excursion would amount to $3.6 \times 10^{17}$ fissions. This is expected to destroy the core and eject all core material into the pit where it burns, greatly adding to the total energy of the excursion. No rupture of reactor shield or building is expected. The reactor pit and reactor building will be heavily contaminated and some radioactive material will escape from the building. It is nearly certain that the maximum radiation dose to personnel outside the reactor building will not exceed 15 roentgens.

Consideration of the design characteristics, possible accidents and method of operation lead to the conclusion that the reactor is fundamentally safe for the following reasons:

1. The temperature coefficient of reactivity is substantially negative.

2. The policy of operation with a fixed loading of limited excess reactivity leaves little opportunity for dangerous personnel error.

3. The interlock system and scram instrumentation are such that a very improbable number of simultaneous failures must occur if a personnel error is to result in a significant excursion. 
4. Both core and blanket are at maximum density; almost any conceivable disturbance reduces reactivity.

5. Even in the event of a severe excursion, the isolation of the site, the prevailing winds, and the low inventory of fission products minimize the number of persons exposed and the severity of their exposure.

\section{INTRODUCTION}

The Argonne Fast Source Reactor (AFSR) is designed as a laboratory tool to augment the research capability of the Idaho Division, Argonne National Laboratory. It will, without interfering with programs of existing reactors, supply stable, reproducible fluxes of both thermal and fast neutrons. The reactor will be used in various ways:

1. To test neutron detectors in development and to calibrate operational counters for use in other reactors.

2. To irradiate foils for the development of advanced foil counting and radiochemical techniques.

3. To check out complex experimental systems ahead of time in order to avoid waste of ZPR-III or other experimental reactor time.

4. To supply fluxes in which can be tested equipment for advanced experiments such as:

a. Measurement of fast neutron spectra

b. Measurement of statistical fluctuations of reactor neutron populations.

The design chosen is expected to accomplish the foregoing economically in terms of both cost and manpower.

Reactor characteristics are summarized in Table I. 
Table I

SUMMARY OF DESIGN CHARACTERISTICS

ARGONNE FAST SOURCE REACTOR

Core

Geometry - solid right circular cylinder

Diameter of uranium, inches including

0.005 inch nickel can

4.50

Length, inches including 0.005 inch nickel can

Material

Critical mass $\mathrm{U}^{235}, \mathrm{~kg}$

Uranium, highly enriched $\sim 20 \mathrm{~kg}$

Blanket

Geometry - hollow right circular cylinder

Outside diameter and height, inches

Thickness, inches

Material

Mass $U^{238}\left(0.2 \% U^{235}\right)$

$20 \frac{5}{8}$

8

Depleted Uranium

$2100 \mathrm{~kg}$

Reactor Cooling System

Design reactor power, watts

1000

Cooling air flow, cfm

55

Pressure drop across core and blanket, psi

6

Air temperature rise across core, ${ }^{\circ} \mathrm{C}$

20

Maximum metal temperature, ${ }^{\circ} \mathrm{C}$

98

Percentage of power produced in core $\quad 80$

Percentage of power produced in blanket 20

Nuclear

Neutron energy

Maximum neutron flux, $\mathrm{n} / \mathrm{cm}^{2}-\mathrm{sec}$

Central fission ratio, $\mathrm{U}^{238}$ to $\mathrm{U}^{235}$

Prompt neutron lifetime

Reactivity Worth:

Control rod, $\Delta \mathrm{k} / \mathrm{k}$

Safety and shim rods (each)

Fuel at radial edge of core, per mole

Effective delayed neutron fraction

Fast

$5.7 \times 10^{11}$

.14

$2 \times 10^{-8} \mathrm{sec}$

$.00313 \Delta \mathrm{k} / \mathrm{k}(46 \not)$

$.00662 \Delta \mathrm{k} / \mathrm{k}(97 \phi)$

$.00532 \Delta \mathrm{k} / \mathrm{k}(78 \varnothing)$

.0068

Biological Shield

Material

Magnetite aggregate

Nominal thickness, ft

concrete, $\left(215 \mathrm{lb} / \mathrm{ft}^{3}\right)$

$4 \frac{1}{2}$ 


\section{A. Reactor Description}

\section{Core}

The core of the Argonne Fast Source Reactor is a right circular cylinder of highly enriched uranium, 4.50 inches in diameter and approximately 4.25 inches high. The estimated critical mass is 20 kilograms. As shown in Figure 1, the core is composed of uranium discs canned in .005 inches nickel to prevent oxidation. The discs are aligned and held in place by stainless steel cages.

The core is divided into two sections. The upper section constitutes about $3 / 5$ of the critical material and has a fixed position and loading. It consists of two uranium discs separately canned and held in position by the upper cage. There is a horizontal $1 / 2$ inch diameter "glory hole" at the approximate reactor center line.

The glory hole is lined with a 5 mil thick nickel tube which is welded at its ends to the nickel can. Surrounding this nickel liner is a tube of zirconium with walls of 10 mil thickness. The purpose of the zirconium is to separate the uranium from the nickel liner so that in a serious excursion formation of a uranium-nickel eutectic will not occur at the center of the core. Otherwise, molten material might collapse into the glory hole, seriously increasing the available reactivity.

The lower $2 / 5$ of the core and the supporting blanket section to which it is attached comprise the safety plug which can be raised and lowered by means of an air cylinder. The lower core section is composed of discs of various thicknesses so that the core loading can be varied.

These discs are attached to the supporting blanket section by means of a second stainless steel cage. The topmost disc has a recess about $1-1 / 4$ inches in diameter by $5 / 32$ inch deep for irradiating foils.

The top disc of the lower section and the two discs of the upper section aggregate about 15 kilograms of fuel. The critical mass will be attained stepwise by adding and subtracting combinations of the following available discs. 


\begin{tabular}{ccc} 
Number of Discs & $\begin{array}{c}\text { Thickness } \\
\text { (inches) }\end{array}$ & $\begin{array}{c}\text { Weight each } \\
\text { (kilograms) }\end{array}$ \\
\cline { 2 - 3 } 5 & 0.300 & $\frac{1.47}{2}$ \\
2 & 0.150 & .73 \\
2 & 0.050 & .24
\end{tabular}

After the exact critical mass has been obtained, the discs required in the lower core section to obtain criticality will be canned in a single can of $5 \mathrm{mil} \mathrm{nickel.} \mathrm{In} \mathrm{addition,} \mathrm{there} \mathrm{is} \mathrm{a} \mathrm{shim} \mathrm{disc} \mathrm{of} \mathrm{uranium}$ 0.100 inches thick canned in nickel; this can be added to the lower core section for a large reactivity increment. Continuous shimming of reactivity over a wide range is obtained from two blanket shim rods to be described later.

\section{Blanket}

The blanket or reflector (Figure 2) of the Argonne Fast Source Reactor consists of a stack of five rings and top and bottom plugs of depleted uranium which form a hollow right circular cylinder 20-5/8 inches outer diameter by $20-5 / 8$ inches high. The walls are 8 inches thick leaving a cavity approximately $4-5 / 8$ inches by $4-1 / 2$ inches which is large enough to provide an annulus for cooling air between core and blanket. The cavity is lined with 20 mil stainless steel to prevent oxidation.

The five blanket rings are drilled for vertical tie rods which provide orientation and rigidity. The center blanket ring which immediately surrounds the core is cut in three pie-shaped sections to reduce the tamping effect in the event of a severe excursion. The reactor assembly (except safety plug) is supported by a one inch steel plate and held in place by the tie rods. The safety plug is bolted to a flange on the end of the air cylinder shaft. Both top and bottom blanket plugs are pierced by $3 / 4$ inch holes which allow air to be circulated through the cooling annulus.

Four vertical 2-1/16 inch holes in the blanket are centered on a radius of $3-9 / 16$ inches from the axis of the reactor. Two holes are for safety rods and two are for shim rods; all are lined with 20 mil stainless steel sleeves. The one-inch control rod operates in a vertical blanket hole located on a radius $3-1 / 16$ inches from the reactor axis. The axis of the one-inch diameter horizontal source hole is radial to the axis of the reactor and lies $2-7 / 8$ inches above the horizontal midplane. The inner end of the source hole is about 3.8 inches from the core axis.

There are three experimental holes in the blanket. The 1/2inch diameter "glory hole", located on the horizontal centerline of the 
core and blanket, is a continuation of the one through the core. The approximately $2-1 / 4$ inch diameter radial beam hole terminates $1 / 2$ inch from the inner edge of the blanket. The centerline of the $1-1 / 16$ inch grazing hole passes $1-1 / 2$ inches from the inner edge of the blanket at the closest point. Access to all experimental holes is by means of stepped plugs in the shield.

\section{Source}

A 15-curie polonium-beryllium neutron source is located in the blanket at the position shown in Figure 2. The source may be manually retracted into the shield by means of a mechanical drive. Limit switches at the "in" and "out" positions operate the source interlock and indicator lights on the control console.

\section{Reactor Layout}

The general arrangement of the reactor, shield, thermal column, sub-reactor pit, experimental and instrument holes, etc. is shown in Figures 3 and 4. All safety and control drive mechanisms are located in the pit and all reactor load changes are made there.

For operating convenience the horizontal centerline of the reactor core, blanket and thermal column is located 36 inches above the floor-line. The reactor support plate is carried on a machined support ring which is cast into the concrete shield. The vertical hole in the shield for receiving the reactor is 24-5/8 inches in diameter leaving an annulus of two inches between blanket and shield. A three-inch space is also provided between the top of the blanket and the bottom of the top shield plug.

\section{Shielding}

The reactor biological shield, shown in Figures 3 and 4 is composed of magnetite aggregate concrete with a density of 215 pounds per cubic foot. The nominal shielding thickness is $4-1 / 2$ feet around and above the reactor. The thermal column shielding plate is $1^{\text {" }}$ steel faced with $1 / 8$ inch of boral. Since the sub-reactor pit will not be occupied during operation, the region below the reactor is only partially shielded. A minimum of two feet of magnetite concrete or its equivalent in ordinary concrete and earth is provided between the pit and the floor outside the shield to absorb neutrons scattered off the pit floor. All experimental and instrument holes through the shield are provided with stepped plugs. The inlet duct for reactor cooling air which penetrated the shield has an offset. 


\section{Thermal Column}

The thermal column, shown in Figures 3 and 4 ,is four feet wide by four feet high by six feet long from blanket edge to end. It is built up of four inch by four inch square bars of reactor grade graphite. The four center longitudinal graphite stringers in the thermal column are removable for experimental purposes. There are two 2 -inch diameter horizontal holes through the graphite, one is two feet and another four feet from the reactor centerline.

\section{Sub-Reactor Pit}

The sub-reactor pit, shown in Figures 3 and 5 is located below the reactor and shield. In this pit will be located the mechanisms for safety rods, safety plug, control rod and shim rods and the lead shield for reloading. Personnel access to the pit is via a $30 \times 36$-inch rectangular manhole in the floor outside the shield and a tunnel three feet wide and six feet high beneath the floor and shield. The walls of the pit, made of ordinary concrete, serve as part of the reactor biological shield foundation. The ceiling is a one-inch thick steel plate used for mounting mechanisms.

\section{Cooling System}

To achieve a 1000 watt capacity, an induced draft air cooling system is incorporated in this design. As shown in Figures 4, 2 and 1 , it has the following flow path: air enters through an inlet filter on the side of the biological shield and passes through an offset duct to the top of the annular cavity between shield and blanket. The air flows down around the blanket to a duct cut into the support plate and safety plug flange. The air then flows up through a $3 / 4$-inch diameter hole in the safety plug, into a $1 / 8$-inch thick axial space below the core, around the core in an annular passage $1 / 16$-inch thick, into a $1 / 8$-inch axial space above the core and out the top blanket plug in another $3 / 4$-inch diameter hole.

From the top of the blanket a duct runs down and under the floor to the blower pit where the air passes through a CWS type absolute filter before entering the positive displacement type blower. From the blower discharge a $2-1 / 2$ inch diameter exhaust runs beneath the floor to a muffler, flow measuring orifice, and stack attached to the side of the 1.uilding. The stack discharges ten feet above the roof peak.

In addition, a separate system provides ventilation to the sub-eactor pit and blower pit. Air is drawn through an intake in the side of the building, through the reactor pit under the floor through a filter in the blower pit, through the blower pit itself, and is exhausted through a 
separate stack by a wall-mounted blower rated at $280 \mathrm{cfm}$ at $2-1 / 4$ inches static pressure. The system removes the heat generated in the blower pit by the reactor cooling blower. It provides ventilation for the subreactor pit so that build-up of radioactivity is minimized and activated dust is collected on the system filter.

A steel mockup of the air path through the blanket and around an electrically heated core was used to determine the following design characteristics at a power of 1000 watts:

Flow

$$
\begin{aligned}
& \text { Pressure Drop } \\
& \text { (Across core and blanket) } \\
& \text { Air temperature rise } \\
& \text { Metal temperature } 1 / 8^{\prime \prime} \text { inside } \\
& \text { core surface } \\
& \text { Central Metal temperature } \\
& \text { (Extrapolated to center of } \\
& \text { uranium core from above } \\
& \text { steel core data) }
\end{aligned}
$$

$55 \mathrm{cfm}$

6 psi

$20^{\circ} \mathrm{C}$

$56^{\circ} \mathrm{C}$ above ambient

$78^{\circ} \mathrm{C}$ above ambient

\section{B. Reactor Control}

1. Four types of control elements are used in the Fast Source Reactor:

a. Two safety rods which decrease reactivity through removal of blanket material.

b. The safety plug which affects reactivity by the movement of core and blanket material.

c. The control rod gives fine control of reactivity through movement of blanket material.

d. Two shim rods physically identical to the safety rods can be adjusted manually only from the sub-reactor pit to compensate for reactivity effects of loading.

\section{Safety Rods}

The two safety rods, located in the blanket, as shown in Figure 2, are 2-inch diameter by 13-1/4 inches long cylinders of depleted uranium with a stroke of six inches. Each rod is connected by an extension shaft through a hole in the lower shield to the rack of the safety rod drive mechanism mounted on the sub-reactor pit ceiling. 
This mechanism, shown in Figure 6, is a modification of the ZPR-III Safety-Control Rod Drive. It consists of a rack and pinion driven through a D.C. magnetic clutch by a gear head motor with magnetic brake. Attached to the lower end of the rack is the piston shaft of a 2-inch diameter pneumatic cylinder which is pressurized to $125 \mathrm{psi}$ on the upper side of the piston. Under normal operation, the motor drives the safety rod at a speed of 4 inches per minute. On a scram signal the magnetic clutch is de-energized and the rod is fired out by the pneumatic cylinder until stopped by the dash pot at the end of its stroke. A. 25 cubic foot capacity accumulator tank stores high pressure air for both safety rod mechanisms. A check valve in the inlet line prevents loss of air in the tank in the event of supply air failure. A drop in accumulator pressure below 100 psi causes scram. A low back pressure regulated at 15 psi (see Figure 8 ) is supplied to assist in decelerating at the end of the stroke. Figure 7 is a scram performance curve for the safety rod mechanism.

\section{Safety Plug}

The safety plug is actuated by a pneumatic cylinder of 4-inch diameter and 43 -inch stroke, with a long cushion dash pot, which is located in a well in the pit as shown in Figure 5. Air to the cylinder is controlled by solenoid valves as shown in Figure 8 . To insert the safety plug, air from a pressure regulator is bled through a 5 -foot length of $1 / 16$ in. I. D. tubing and through a second pressure regulator to the lower end of the air cylinder The pressure regulator input to the small bore tube is adjusted (to 40 psi) so that the air flow will cause the cylinder to travel at 18 inches/minute. This regulator is secured by key lock against tampering. The second regulator, which follows the small bore tube, is set at about 20 psi so that the static pressure will not $\mathrm{rise}$ high enough to damage the arm which enge es the jack. It is backed up by two relief valves. When the safety plug is six inches from its "up" position, an arm on the air cylinder shaft engages the lower end of a mechanical jack. The jack (Figure 9) is then backed off at a speed of $2 \mathrm{in} / \mathrm{min}$ until it is $1-1 / 4$ inches from the "up" position; thereafter, it moves at $1 / 4 \mathrm{in} / \mathrm{min}$ until fully "up." The cylinder air pressure forces the plug to follow the jack. The design of the jack is unusual in that it changes the speed at which the plug rises without change of gear ratios or recourse to separate electric motors actuated by limit switches at the changeover point. This added reliability is attained by using a single gear train to drive two separate screws: the outer (low speed) screw, and inner, non-rotating (intermediate speed) screw. The speed change is accomplished by so adjusting the device that the safety plug follows the inner screw from 6 inch to $1-1 / 4$ inch separation at which point contact is shifted to the slow motion outer screw which the safety plug then follows to the fully assembled position. 
For slow shutdown the low pressure air supply valve is shut off and the lower end of the air cylinder is vented to the air so that the plug descends under its own weight. On a scram signal solenoid valves are de-energized to admit high pressure (125 psi) air to the cylinder above the piston simultaneously venting the cylinder below the piston, and firing the safety plug downward. Figure 8 a gives the safety plug scram performance curve. The jack automatically runs out to meet interlock requirements for next startup. A separate accumulator tank of $2-1 / 2$ cubic foot capacity stores air for the safety plug cylinder alone. A pressure switch scrams the reactor in the event air pressure falls below 100 psi in the accumulator for the safety plug.

\section{Control Rod}

The control rod is a one-inch diameter by $12-1 / 4$ inches long cylinder of depleted uranium. It is located in the blanket, as shown in Figure 2. It has a stroke of six inches, a speed of three inches a minute, and does not scram. The control rod is connected by an extension shaft through the lower shield to a lead screw and nut mechanism mounted on the pit ceiling, as shown in Figure 10. A gear head motor with magnetic brake drives the lead screw. The position indicator synchro is geared off the lead screw.

\section{Shim Rods}

The two shim rods are physically the same as the safety rods, but are operated manually by a nut and screw mechanism (Figure 11). They can be operated only from the pit when the reactor is shut down. Their single drive can be locked by key to prevent tampering or unauthorized movement. The purpose of these rods is to provide latitude of reactivity adjustment to compensate for changes caused by experiments in the access holes.

\section{Control Circuits}

The Argonne Fast Source Reactor is controlled from a console (Figures 12 and 13) located in a corner of the building. In the console are located the following operating controls and indicators:

a. Control power key switch.

b. Two safety rod motor switches (spring loaded), "in" and "out" lights, and position indicators.

c. Safety plug air cylinder operating buttons, "up" and "down" lights, jack motor switch (spring loaded), position indicator, jack contact light. 
d. Control rod motor switch (spring loaded), "in" and "out" light, position indicator.

e. Scram button.

f. Slow shutdown button and light.

g. Annunciator panel to indicate cause of scram, open holes, and high radiation level. Includes alarm horn and provision for bypassing interlocks on cooling air and source.

The reactor has a number of startup and scram interlocks to assure proper operation. An annunciator light panel indicates which interlock causes scram. Combined with the annunciator panel is an interlock bypass and indicator light system for jumpering out source and cooling air interlocks by means of key actuated switches marked " $J$ " in the following tabulation. Both of these systems are in full view of the operator. Thus, it is possible to operate the reactor with no cooling air when temperature stability is desired at very low power. Certain statistical experiments at very low power require operation without the source because of the perturbation it represents to the small neutron population. The source may be removed only after criticality is attained.

7. Scram Interlocks

The following occurrences cause scram:

a. High power level (two circuits)

b. Short period, i.e. less than 15 seconds, (two circuits)

(J) c. Source leaves "in" position

(J) d. Reactor cooling blower goes off

e. Scram air pressure drops below 100 psi in either accumulator

f. Safety plug leaves "up" position or contact with jack except on slow shutdown

g. Fuel temperature reaches $120^{\circ} \mathrm{C}$

h. Power failure - control D.C. or instrument A.C.

i. Failure of chamber high voltage 


\section{Startup Interlocks}

be met:

In order to start up the reactor the following conditions must
a. Source in the reactor
b. Reactor cooling blower and pit exhaust blower both on unless interlock is jumpered
c. Scram air pressure above 100 psi
d. Safety plug jack in "out" position
e. Control rod in "out" position
f. Safety and period circuits reset
9. Startup Sequence

After the startup interlocks are satisfied, the sequence requirements permit only the following order of events:
a. Insert safety rods
b. Raise safety plug to "up" position
c. Insert control rod.

\section{Alarm Interlock}

Any of the following occurrences will sound an alarm and be indicated by the annunciator panel:
a. High radiation level in sub-reactor pit
b. High radiation level in reactor cooling exhaust filter
c. High stack activity
d. Opening pit manhole or any of the horizontal holes in the shield.

C. Reactor Instrumentation

The reactor instrumentation (Figure 14 is a schematic) includes:

1. One pulse counter $\left(\mathrm{BF}_{3}\right)$ channel with scaler (additional channels will be used for initial loading).

2. One ion chamber and linear amplifier channel with recorder for operational control. 
3. Two ion chamber and linear amplifier channels with power level trip and indicating meters.

4. Two ion chambers and logarithmic amplifier channels. These channels operate the period meter, period scrams, and a dual pen recorder for log power and period.

The reactor also has the following temperature instrumentation:

5. One fuel temperature thermocouple with pyrometer trip circuit.

6. One thermocouple selector switch and indicating pyrometer for the following temperatures:
a. Inlet air
b. Outlet air
c. Blanket - inner edge
d. Blanket - outer edge

All of the amplifier chassis, meters, indicators, recorders, etc. for the above items are located in the control console.

Ion chambers are two inch diameter, $\mathrm{B}^{10}$ coated, parallel plate type. They are located in vertical holes, as shown in Figure 4, either in the shield or thermal column. The $\mathrm{BF}_{3}$ pulse counter is located in one of the vertical holes in the thermal column.

\section{Reactor Physics}

in Topsy. (1) Onysics calculations are based on the empirical data obtained the same composition as the Argonne Fast Source Reactor. Extensive substitution experiments were performed in this assembly and it is from them that the worths of rods and holes were calculated. The Topsy spherical data are an excellent approximation for the worths along the axis and along a midplane radius in a $1: 1$ cylinder. For other positions a chopped $(\cos )^{2}$ weighting was used. Streaming effects were neglected.

Another Topsy assembly was a pseudocylinder having the same composition as the pseudosphere and very nearly the design dimensions of the Argonne Fast Source Reactor. The critical mass was 18 kilograms, but there being no substitution data available, it was necessary to correct for voids with values obtained from the Topsy sphere as described above. The estimated critical mass is 20 kilograms. The worths of the various rods and holes are tabulated in Table II. 
Table II

\section{REACTIVITY EFFECTS}

$\underline{\text { Item }}$

Control Rod

Safety (or shim) Rod

Minimum Fuel Increment before canning

Shim disc

Gap Worth

Glory hole

Beam Hole

Grazing Hole

Cooling Annulus

Foil Recess

Effective Delayed

Neutron Fraction

\section{Description}

1 "diameter 6" effective length

$\frac{\mathrm{dk}}{\mathrm{dt}}$ at normal insertion rate of 3 " per minute

2 " diameter 6 " effective length

$\frac{d k}{d t}$ at normal insertion rate of 4 " per minute

$4 \frac{1}{2}$ " diameter $\times .050 "$ thick

Worth $\Delta \mathrm{k} / \mathrm{k}$

0.0031

$0.000026 \mathrm{sec}^{-1}$

0.0066 per rod

$0.000075 \mathrm{sec}^{-1}$

0.0041

$4 \frac{1}{2} "$ diameter $\times 0.100 "$ thick

0.0082

$.050 "$ gap between safety plug and stationary fuel

0.0044

$\frac{d k}{d t}$ when safety plug rises normally $1 / 4$ " per minute

$0.00037 \mathrm{sec}^{-1}$

$\frac{d k}{d t}$ when safety plug rises at $2 "$ per minute

$\frac{d k}{d t}$ when safety plug rises at 18 " per minute

$0.0029 \mathrm{sec}^{-1}$

$0.027 \mathrm{sec}^{-1}$

$1 / 2$ " horizontal hole thru center of core and extending thru blanket (worth of hole - void versus $\mathrm{U}^{235}$ in core $\mathrm{U}^{238}$ in blanket)

0.0132

$2 \frac{1}{8}$ " horizontal hole in blanket extending toward core center and dead ending $1 / 2$ " from core edge (void versus $\mathrm{U}^{238}$ )

$1 \frac{1}{16}$ " horizontal tangential hole in blanket passing $1 \frac{9}{16} "$ from core edge (void versus $\mathrm{U}^{238}$ )

0.00068

$1 / 16^{\prime \prime}$ around core $-1 / 8$ " above and below core

(void versus $\mathrm{U}^{235}$ )

$1 \frac{1}{4}$ " diameter $\times 5 / 32$ " deep on core axis and $1 / 2$ " below mid plane (void versus $U^{235}$ )

0.0127

0.0030

0.0068

* After initial evaluation, the potential reactivity effect of this hole will be reduced to $.0007 \frac{\Delta \mathrm{k}}{\mathrm{k}}$ by means of the spacer assembly shown in Figure 16. 


\section{E. Reactor Building}

The building to house the Argonne Fast Source Reactor is located near the present ZPR building as shown in Figure 15. The AFSR building has its own heating plant and air compressor. There is no water plumbed into the building.

Figure 16 shows the Argonne Fast Source Reactor Building, a 32 foot by 32 foot by 20 foot high, prefabricated Butler-type building. The interior of the building is insulated with $1-1 / 2$ inches of fiber glass and will be lined with corrugated steel to a height of 10 feet. Two personnel doors and a 12 foot by 13 foot overhead freight door make this building easily accessible for personnel and vehicles. A 480 volt, 3 phase, 60 cycle power supply of 100 ampere capacity is brought over from the main ZPR circuit breaker through a 100 amp breaker. Five separate branchbreakers will then control circuits for the building exhaust blower, reactor cooling blower, crane, welding receptacles, and lighting and instrument power and reactor control power (AC).

Calculations indicate that as much as $42,500 \mathrm{Btu} / \mathrm{hr}$ of heat may be liberated by instruments, light, personnel, etc. in this building. To maintain a comfortable summer air temperature in the building this heat must be removed by ventilation and a complete change every two minutes will be required. The two gable mounted exhaust blowers, equipped with automatic louvres, have a combined capacity of $9500 \mathrm{~cm}$.

The air supply for controls comes from the compressor installed for that purpose. Air (125 psi minimum) from the compressor tank will be stored in two accumulator tanks of $2.5 \mathrm{ft}^{3}$ total capacity located in the reactor pit. This will be adequate for scramming, even in the event that compressor service is interrupted.

F. Site

This facility is located in the same exclusion area as the Zero Power Reactor III and Experimental Breeder Reactor I at the National Reactor Testing Station in Eastern Idaho. Figure 17 is a site map showing the location in relation to other site installations. The nearest populated off-site areas are Arco, (population: about 2000) about 18 miles west northwest and Atomic City, (population: about 200) about 12 miles southeast. Except for EBR, BORAX and ZPR-III (extant Argonne facilities) the nearest populated location is Central Facilities, three and one-half miles northeast. The nearest approach of U.S. Highway 20 is about $1-3 / 4$ miles to the northeast. 
The site is a desert plain of volcanic origin; its elevation averages about 5000 feet. The annual precipitation averages about $7-1 / 2$ inches of which a major portion falls as snow. The porous volcanic surface absorbs water so readily that there is negligible surface drainage. The water absorbed sinks to the water table at a depth of about 600 feet where it is diluted by the waters of the Big Lost and Little Lost Rivers and Birch Creek which end their courses by sinking along the northwest edge of the site through the volcanic plain to an impervious stratum.

Air masses reaching this area must pass over mountain barriers where a large share of their moisture is precipitated. As a result, site relative humidity is normally very low, perhaps $20 \%$ on a summer afternoon. The low humidity together with the altitude permits intense solar surface heating during the day and rapid radiation at night giving large diurnal temperature variations, typically $30^{\circ} \mathrm{F}$. The extreme temperature range for the site is considered $-45^{\circ}$ to $105^{\circ} \mathrm{F}$.

Figure 18 is the wind rise at the 20 foot level at Central Facilities for November 1952 through December 1956. There is little difference in seasonal wind behavior. Typically the stronger southwest and west southwest winds occur at or after the hottest part of the day while the northeast and north northeast winds tend to occur at night or very early morning. 


\section{MANAGEMENT OF THE REACTOR}

Optimum employment of the reactor requires that it be readily available to staff members requiring its flux in their work. The mode of operation described here is designed to meet the above criterion insofar as is compatible with safe operation.

\section{A. Staff}

1. A Chief Physicist designated by the Idaho Division Director will be responsible for the safe operation and proper use of the reactor. $\mathrm{He}$ and his alternates will be thoroughly familiar with the physics and functioning of the reactor.

2. Staff members who may need to use the reactor will be designated qualified Supervisors by the Division Director when, in his judgment, they have had sufficient training to oversee operation.

3. The Division Director will designate a reasonable number of qualified technicians as operators who will normally handle actual operation of reactor controls.

4. A minimum of two persons will be required to operate the reactor :

a. A staff member (Chief Physicist, Alternate Chief Physicist or Qualified Supervisor).

b. A qualified technician operator.

B. Initial Startup

1. The initial startup will be made under the supervision of the Division Director or Chief Physicist.

2. For initial startup the two upper core pieces will be canned in final form, but the discs making up the lower core section will be left bare so that they can be loaded incrementally to obtain the critical mass.

3. The principal reactivity measurements will then be made, including worths of all rods, worth of fuel, worth of gap, and the temperature coefficient of reactivity.

4. The beamhole liner shown in Figure 19 will be fabricated with the length of the spacer section adjusted so that the reactivity change 
caused by filling the beam hole with solid blanket material will be less than $0.0007 \frac{\Delta \mathrm{k}}{\mathrm{k}}$.

5. The reactor will be shut down and the fuel discs necessary to form a critical mass will be removed and canned as one unit.

\section{Operation}

1. The Chief Physicist and Division Director will each have custody of a set of all reactor keys, including those to reactor control power switch, the glory hole, the shim rod adjustment, the two jumperable interlocks, and the pressure regulator controlling the speed of the air cylinder.

2. Normally the shim rods will be adjusted so that period with the control rod fully inserted will not be shorter than 30 seconds.

3. For a routine experiment, a qualified supervisor may obtain the approval of the Chief Physicist, be issued the control power key, and proceed with his work with the aid of one operator.

4. For a non-routine experiment requiring:
a. Use of glory hole
b. Adjustment of shim rods
c. Insertion or removal of shim disc
d. Power level over 50 watts
e. Period shorter than 30 seconds

the interested supervisor will describe the experiment in writing with copies to Division Director and Secretary of Idaho Division Committee on Reactor Safety and obtain the written approval of the Chief Physicist together with the appropriate keys.

5. Where he judges it desirable, the Chief Physicist will personally supervise the experiment.

6. Although the reactor has been designed for operation at a nominal maximum power of 1000 watts, it is easily possible that there has been overdesign in cooling and shielding. The actual maximum power level set for the reactor will be that power at which the shielding is adequate to keep the operating area below tolerance radiation level and also at which the cooling system is adequate to keep the maximum fuel temperature below $120^{\circ} \mathrm{C}$. 


\title{
SECTION III
}

\author{
HAZARDS
}

\section{A. General}

Both reactor design and use militate for safety. The critical loading must be established in the usual stepwise fashion, but once the critical loading is found and shim rods adjusted, there is little need for varying the reactivity beyond the range available in the control rod. The temperature limitation of $120^{\circ} \mathrm{C}$ means very little excess reactivity is required to override the thermal effect on reactivity. The nominal power will permit an almost limitless operating life without significant effect on reactivity. In the event that the shim rods must be moved to adjust reactivity for a specific experiment, their adjustment is subject to checking by at least the Supervisor and Chief Physicist.

The design and density of the core and blanket are such that almost any credible deformation or heating of the reactor reduces reactivity.

The extensive measurements done on Topsy (LA-1708) form a sound basis for estimates of critical mass and reactivity effects. $\mathrm{S}_{4}$ calculations for a spherical idealization of the actual reactor give a thermal coefficient of reactivity of $-9.4 \times 10^{-6} /{ }^{\circ} \mathrm{C} \Delta \mathrm{k} / \mathrm{k}$ for adiabatic heating of the core; i.e., when heating takes place so quickly that the core expands outward in the cooling annulus without any corresponding heating and expansion of the blanket. For more gradual heating, the expansion of the blanket increases the effect.

It was not certain that the $\mathrm{S}_{4}$ calculations gave good results for a core expanding into an annular void, and further runs were made on a core-blanket system with no annulus. The temperature coefficient for a reactor having an annular void was found to be one-third that of similar system without the void. A rough mock-up of the system was assembled in $\mathrm{ZPR}$-III and reactivity measurements were made on the critical configuration. First, the core was expanded in one dimension into a void and the reactivity change measured. Then, a reactivity measurement was made in a situation in which (there being no void) the core and blanket were moved together in a simulated expansion. Both cases exhibited a negative reactivity effect with the "void" case having about one-third the effect of the "no-void" case. Since this was one-dimensional experiment on a crude mock-up, it can only be considered qualitative confirmation of the $\mathrm{S}_{4}$ calculations. 
In view of the recent work by Kato and ButPer, ${ }^{(3)}$ the Doppler effect on reactivity is considered negligible.

Although the critical mass is estimated as 20 kilograms, 25 kilograms of fuel will be fabricated. Except for one shim disc of 480 grams, all excess fuel will be returned after the critical mass is determined and lower core section canned.

Installation of fuel pieces is free of nuclear hazard under any imaginable conditions. Each of the two canned sections comprising the stationary upper portion of the core weigh on the order of 7 kilograms; either separately or together, they are comfortably below the minimum critical mass for dense metallic uranium-235 (about 17 kilograms in an infinite blanket of maximum density natural uranium and somewhat more in a hydrogenous blanket). (4) Once the stationary part of the core has been installed, the remaining 11 kilograms are likewise safe to handle outside the reactor. Initial loading steps can be as low as $240 \mathrm{gms}$ or a $\Delta \mathrm{k}$ of 0.0041 .

\section{B. Method of Calculation}

A number of excursions (summarized in Table III) have been calculated and are discussed in the various appendices.

Table III

SUMMARY OF EXCURSIONS STUDIED

\begin{tabular}{|c|c|c|c|c|c|}
\hline Appendix & Graph & $\Delta \mathrm{k} / \mathrm{k}$ & $\mathrm{dk} / \mathrm{kdt}\left(\mathrm{sec}^{-1}\right)$ & $\begin{array}{l}\text { Time Between Delayed } \\
\text { Critical and Prompt } \\
\text { Critical (sec) }\end{array}$ & Failures* \\
\hline I & $F_{1 g} \quad 18$ & 010 & 0004 & 17 & $\mathrm{ABCD}$ \\
\hline I & Fig 19 & 029 & 0004 & 17 & $A B C D$ \\
\hline I & Fig 20 & 009 & 003 & 23 & $A B C E$ \\
\hline I & $F_{i g} 21$ & 027 & 003 & 23 & $A B C E$ \\
\hline I & $F_{1 g} 22$ & 089 & 03 & 023 & $A C F$ \\
\hline III & & 0023 & 000026 & ---- & ABCD \\
\hline ㅍI & & 0043 & (0043 step) & $-\cdots$ & $A B C D$ \\
\hline
\end{tabular}

* The scram interlock or control fallures which must occur to allow the excursion in question to lead to a serious incident are listed below together with the 1dentifying letter for use in the Table

A Both period meters fail to scram on short period

B Operator falls to act on short period, high power, or high temperature indications or the instruments fail to indicate the condition of the reactor

C Both power level safety c1rcuits fall to scram on the high power level

D The temperature circuit fails to scram on high temperature

E Jack fallure permits assembly at intermediate speed of two inches per minute

F Jack runout feature falls and interlock falls on jack down requirement for startup 
The basic excursion problems were worked on Argonne's IBM 650 Computer using Code RE29. ${ }^{(5)}$ Code RE29 yields the space independent behavior of a system in which

$$
\frac{d k}{d t}=A+B n
$$

where $A$ is a constant representing the slope of a reactivity input ramp and $B$ is the coefficient relating power (proportional to neutron population) to time rate of change of reactivity. B can be obtained as follows:

We approximate the fission rate (fission $/ \mathrm{sec} / \mathrm{cm}^{3}$ ) as $\frac{\mathrm{n}}{\nu \ell}$ where

$\mathrm{n}$ is the population of neutrons $/ \mathrm{cm}^{3}$

$\nu$ is neutrons/fission (2.5)

$\ell$ is prompt neutron lifetime $\left(2 \times 10^{-8} \mathrm{sec}\right)$

$$
\begin{aligned}
\frac{\mathrm{dE}}{\mathrm{d} t} \mathrm{~cm}^{3} & =\frac{\mathrm{n}}{\nu \ell} \frac{.24}{3.1 \times 10^{10}}=\mathrm{n} \times 1.55 \times 10^{-4} \text { calories } / \mathrm{cm}^{3} \\
\frac{\mathrm{d} \theta}{\mathrm{dt}}=\frac{\mathrm{dE}}{\mathrm{dt}} \mathrm{cm}^{-3} \times \frac{1}{\text { specific heat } \times \text { density }} & \\
= & \frac{\mathrm{n} \times 1.55 \times 10^{-4}}{.035 \times 19}=\mathrm{n} \times 2.3 \times 10^{-4} \mathrm{degree} \mathrm{C} / \mathrm{sec} \\
\mathrm{Bn}=\frac{\mathrm{dk}}{\mathrm{dt}} & =\frac{\mathrm{d} \theta}{\mathrm{dt}} \times \frac{\mathrm{dk}}{\mathrm{d} \theta}=\mathrm{n} \times 2.3 \times 10^{-4}\left(-9.4 \times 10^{-6}\right) \\
B & =-2 \times 10^{-9}
\end{aligned}
$$

These results were then extrapolated to a spherical idealization of the actual reactor by means of the power distribution obtained in the previously mentioned $\mathrm{S}_{4}$ calculation. Figures 20 through 24 represent the predicted behavior of this spherical ideal:
Core radius
$6.13 \mathrm{~cm}$
Critical mass
$18.1 \mathrm{~kg}$
Annular void
$0.2 \mathrm{~cm}$
Effectively infinite blanket

The solid temperature curves represent the limiting values which pertain to the case of no heat conduction. However, depending on the time scale of the excursion, conduction may substantially ameliorate the indicated temperature. In any event, as the outer portion of the core melts, the fuel mass collapses into contact with the blanket; the core 
boundary is then held at or below the melting point of uranium because of the heat sink represented by the heat of fusion in the massive uranium blanket material.

\section{Types of Incidents Considered}

1. Appendix I covers five excursions which might arise from errors in loading, coupled with operator error and/or failures of interlocks or scram circuits.

(a) The reactor having been overloaded by about $1 / 2 \mathrm{kilogram}$ goes critical when the safety plug is 0.1 inches from the fully assembled position and moving at the slow assembly speed of $1 / 4$ inch per minute. If multiple personnel and circuit failures occur, an excursion such as is plotted in Figure 20 may be observed. The excursion results in some melting of the core and contamination of the reactor pit. The reactor cooling system and pit ventilation will probably prevent contamination from reaching the floor level of the building. The maximum personnel exposure will be about $10 \mathrm{mr}$.

(b) The reactor having been overloaded by about I $\frac{1}{2}$ kilograms goes critical when the safety plug is about 0.3 inches from the fully assembled position. The conditions are otherwise the same as in the foregoing case. The results are plotted in Figure 21. There is severe melting of the core but probably no vaporization or disruption of the blanket. Maximum exposure of operating personnel is about $21 \mathrm{mr}$.

(c) Figure 22 is a plot of the core in which the reactor becomes critical at 0.1 inches (about $1 / 2$ kilogram overload) and the safety plug is traveling at the intermediate speed of 2 inches per minute. The integrated excursion is of the same size as the one described in (a) above.

(d) Figure 23 is a plot of the predicted excursion in which the reactor becomes critical at a separation of about 0.3 inches while the safety plug is traveling at 2 inches per minute. The results are essentially those for the same overload and slow speed as sembly in (b) above. The shortened time scale does decrease the effect of conduction and there will probably be some vaporization of fuel. 
(e) Figure 24 represents the predicted behavior in the severe case in which the reactor, overloaded by about 5 kilograms goes critical when the safety plug is one inch from the fully assembled position and traveling upward at the air cylinder speed of 18 inches per minute. This results in a violent excursion which is terminated by blowing the safety plug downward. The molten core ejected into the pit burns with the liberation of a great amount of chemical energy. The reactor is destroyed and the pit and tunnel are heavily contaminated. Radioactive material will be blown out into the reactor building through the reactor ports and particularly the manhole. Some contamination will probably reach the outside through the pit ventilation ducts.

Although it is reasonable to expect that fission products will be largely contained in the pit and building, Appendix I estimates that the hazard to other personnel is not severe even in the case of gross release of a radioactive cloud.

2. Appendix $\Pi$ is concerned with excursions which might arise from human failure in reactor operations combined with failure of various scram circuits.

(a) In the first case the properly loaded and functioning (except for power level and temperature trips) reactor runs out of control due to an inattentive or suddenly disabled operator. This excursion is limited to about 3600 watts power level by the negative temperature coefficient even if the power level trips fail to scram. The core average temperature reaches about $265^{\circ} \mathrm{C}$. No damage is anticipated and the shielding is adequate to guarantee that personnel exposure will not exceed $30 \mathrm{mr}$ per hour until the reactor is shut down.

(b) The second case is one in which poor teamwork between an experimenter and the operator result in the sudden addition of $2.0 \times 10^{-3} \Delta \mathrm{k} / \mathrm{k}$ while the reactor is on a minimum allowable period of 15 seconds. If both period trips, both power level trips, and the core temperature trip fail, the power is limited by the negative temperature coefficient to about 7000 watts and an average core temperature of $480^{\circ} \mathrm{C}$. No damage to the reactor is anticipated and maximum personnel exposure is at the rate of about $50 \mathrm{mr}$ per hour until the reactor is shut down. 
D. Hazard in Retrieving Foils

The principal hazard in normal operation appears to be the radiation received when retrieving foils from the lower core section after a run at sustained power. A calculation was made of the radiation levels to be expected after a one hour run at one kilowatt power. The radiation level 100 seconds after termination of the run at a point 2 centimeters above the lower core section (approximate position of hand in removing foils without tools) is of the order of $5 \times 10^{4}$ roentgens per hour. At 1000 seconds after the end of the irradiation, the level is about $1.5 \times 10^{4}$ roentgens per hour.

The lead ring and blanket section of the plug constitute a fairly good, although open-topped, gamma shield. The radiation level at a horizontal distance of one meter from the shield (within reasonable operating distance with tongs) is about 0.8 roentgens per hour 100 seconds after radiation. Thus, foils can be retrieved without excessive exposure provided caution is exercised to avoid the direct beam from the top of the core section. In doubtful cases involving intensive irradiation, smaller foils can be exposed in the glory hole, from which they can be retrieved with virtually no personnel exposure.

E. Miscellaneous Hazards

1. Since both core and reflector are at maximum density, it is extremely unlikely that an earthquake, no matter how severe, could in itself increase reactivity by some displacement of reactor components. However, there is the possibility that an earthquake might in some way freeze the controls when the reactor is on a 30 second period; the negative temperature coefficient will compensate the 60 inhours excess reactivity when the temperature has risen about $160^{\circ} \mathrm{C}$. This corresponds to an equilibrium power of 3000 watts if the air flow is maintained and something much less if the cooling air stops.

2. Flooding is not credible in view of the NRTS meteorology and the siting of the reactor. The cooling air intake is about 3 feet above the floor so that local water from freakishly melting snow cannot be drawn into the reactor, even in the remote event that it might $r$ un onto the reactor building floor. The filter on the cooling air intake prevents any solid material from being drawn into the reactor by the air stream.

3. The reactivity of the cooling air is negligible. At nominal power of 1000 watts, carbon-14 (half-life 5600 years) will be produced at the rate of $10^{-14}$ curies per second by the reaction $\mathrm{N}^{14}(\mathrm{n}, \mathrm{p}) \mathrm{C}^{14}$. Nitrogen 16 (half-life 7.4 seconds) will be produced by $\mathrm{O}^{16}(\mathrm{n}, \mathrm{p}) \mathrm{N}^{16}$ at the rate of about $5 \times 10^{-8}$ curies second. 


\section{CONCLUSIONS}

The following points can be made concerning the safety of the Argonne Fast Source Reactor:

1. The temperature coefficient is negative, $-9.4 \times 10^{-6} \Delta \mathrm{k} / \mathrm{k}$ per ${ }^{\circ} \mathrm{C}$.

2. The policy of operating with a fixed loading of limited excess reactivity leaves little opportunity for dangerous personnel error. Significant changes in reactivity are rigorously controlled by locking the glory hole and shim rods.

3. The interlock system and scram instrumentation are such that a very improbable number of simultaneous failures must occur if a personnel error is to result in a significant excursion.

4. Both core and blanket are of maximum density metal; any credible distortion reduces reactivity.

5. In the event of a severe excursion the isolation of the site, the prevailing winds, and the low inventory of fission products all tend to reduce the number of persons exposed and the severity of exposure. 


\section{$\underline{\text { REFERENCES }}$}

1. LA-1708 "Material Replacement in Topsy and Godiva Assemblies"

2. De Marrais, G. A.

"The Climatory of the National Reactor Testing Station" IDO- 12003

3. Kato, W. Y. and Butler, D. K.

"Measurement of the Doppler Temperature Effect in an EBR-I Type Assembly" ANL-5809

4. Paxton, H. C.

"Critical Masses of Fissionable Metals as Basic Nuclear Safety Data" LA-1958

5. Brittan, R. O.

"Some Problems in the Safety of Fast Reactors" ANL-5577

6. AECU 3066 "Meteorology and Atomic Energy"

7. Orndoff, J. D., Nuclear Science \& Engr. 2,450 (1957) 


\section{APPENDIXI}

\section{LOADING ERROR WITH MACHINE FAILURE}

1. The least improbable case is that in which the reactor with controls operating normally, goes critical while the plug is moving upward at the slow final assembly speed of $1 / 4$ inch per minute. This corresponds to a reactivity addition rate of $.0004 \Delta \mathrm{k} / \mathrm{k}$ per second, giving 17 seconds from delayed to prompt critical. For this situation to lead to an accident, the following failures must occur.

a. Both period meters fail to scram on the excessively short period.

b. Operator fails (17 seconds between delayed and prompt critical) to act on short period, high power, and high temperature indications, or the instruments fail to indicate the condition of the reactor.

c. Both power level safety circuits fail to scram on the excessive power level.

d. The temperature safety circuit fails to scram on the high temperature.

The behavior of the reactor going critical when the safety plug is still 0.1 inches from the fully assembled position under the above as sumptions is plotted in Figure 20. This corresponds to an overload of about one-half kilogram.

At 30 seconds the reactor power is about 4200 calories/second (17.5 kilowatts) and slowly decreasing. The total integrated power is $1.1 \times 10^{6}$ calories (4.6 $\times 10^{6}$ watt-seconds or $1.4 \times 10^{17}$ fissions) and the decreased power level is adding to the integrated power very slowly. The reactor eventually becomes subcritical through any, or a combination, of the following:

a. Loss of core material by molten flow through the lower air hole or glory hole.

b. Loss of core material through oxidation.

c. Loss of core enrichment by admixture of uranium-238 melted from the blanket.

The reactor shield is designed to give less than $7.5 \mathrm{mr}$ per hour at nominal power (1000 watts) at any point against the outside of the shield. This corresponds to a total integrated power of $3.6 \times 10^{6}$ watt-seconds per hour; so the maximum personnel exposure from this excursion would 
be about $10 \mathrm{mr}$, excluding internal hazard from fission products that might be scattered about. Most fission products formed should be contained by the reactor air cooling system filter and pit ventilation system filter if the fans continue operation. In any event the fission product release is small since the core does not vaporize and the blanket and shield are not dis rupted.

The foregoing must be qualified by the uncertainty as to the behavior of the uranium pieces in intimate contact with the nickel cans. The U-Ni eutectic has a melting point $\left(738^{\circ} \mathrm{C}\right)$ much lower than that of pure uranium. As a result, it is possible that localized melting may take place on the uranium surfaces in contact with the can sooner than predicted by the graph. The overall effect of eutectic formation should be small since the amount of nickel is small and it is not intimately mixed with the uranium. No serious increase in reactivity can occur by early collapse of material into the glory hole because the glory hole liner is separated from the fuel by 10 mils of zirconium.

2. Figure 21 is a similar plot of the case in which the reactor at the same slow speed goes critical approximately 0.3 inches from the fully assembled position. This occurrence depends on the same instrumental and operator failures as were enumerated in the preceding case. This amount of excess reactivity corresponds to an overload of about one and one-half kilograms of fuel. Again the solid temperature lines represent the limiting adiabatic case. The dotted line is the actual behavior of the core surface temperature. In all probability the time scale is long enough that conduction substantially reduces the temperature from the simple prediction plotted and probably no vaporization occurs.

The total integrated power in this excursion is about $2.5 \times 10^{6} \mathrm{cal}$ ories ( $1.0 \times 10^{7}$ watt-seconds or $3.1 \times 10^{17}$ fissions). The maximum external (gamma and neutron) radiation exposure of operating personnel is about $21 \mathrm{mr}$.

3. Figure 22 is plotted for the case of $1 / 2$ kilogram overload in which the speed change fails and the jack retracts at its high speed of two inches per minute.

The jack is designed to make the speed change mechanically certain; however, improper assembly and incomplete testing of the jack might permit incorrect location of the speed changeover point. Should this permit assembly at the higher jack speed, the reactor would go critical 0.1 inch from the fully assembled position at the rate of $0.003 \mathrm{\Delta k} / \mathrm{k}$ per second. (2.3 seconds between delayed and prompt critical). The same instrumental and operational failures apply as in the preceding cases except that the thermocouple may be too slow to act. It is seen that the net result in terms of total integrated power is virtually the same as in Figure 20. 
4. Figure 23 shows the case in which the reactor goes critical 0.3 inches from the fully as sembled position ( $1 \frac{1}{2}$ kilogram overload) at the same assembly rate of two inches per minute. Otherwise, the situation is the same as in the preceding case. The integrated total power of the excursion is the same as in Figure 21 , in which the same amount of reactivity was added at the slow rate of assembly. However, the faster time scale reduces the effect of conduction at the peak of the excursion and some vaporization may occur.

In all of the foregoing cases the temperature rise is on the time scale of several seconds so that it is unlikely that any shock-like thermal expansion will affect the reactivity.

5. Figure 24 is a plot of expected behavior when, in addition to the other failures mentioned in (1) above, the jack automatic runout provision and associated interlocks fail. In this case, the reactor is assumed to go critical one inch from the fully assembled position corresponding to about 5 kilograms overload (extra fuel discs will no longer be available after the critical loading has been determined) at the speed of the air cylinder (1 8 inches/minute). This adds reactivity at the rate of $0.03 \Delta \mathrm{k} / \mathrm{k}$ per second. Peak power is of the order of $2.3 \times 10^{6}$ calories per second. If all the heat goes to vaporize fuel, it will vaporize $5.7 \times 10^{3}$ grams per second which corresponds to 550 liters (STP) or about 8000 liters per second at the existing tempe rature.

The safety plug unit, including piston and piston rod, weighs about 150 pounds. Since it is moving upward at a constant rate of 18 inches per minute, all forces are in equilibrium and a downward force will tend to reverse its motion. The above figures indicate that at 1.50 seconds after achieving criticality there is adequate vapor production to expel the safety plug downward.

The segmented ring of the blanket surrounding the core may also be pushed outward by the explosive evolution of gas. However, the sudden expansion of these ring segments is opposed by an inertial loading of about 15 pounds per square inch. the friction with adjacent rings, and the shear strength of one $1 / 2$ inch steel tie bolt or dowel. By contrast the expulsion of the safety plug is opposed, for that short travel which is significant to reactivity, only by an inertial loading of about 9 pounds per square inch.

It was hypothesized that the reactor became critical at a safety plug separation of one inch. At 1.50 seconds the plug is still less than half an inch beyond the point of criticality; thus less than half an inch of downward motion will reduce the reactor below critical. However, the violent downward thrust will carry the plug below the blanket so that the molten 
uranium is scattered. The loss of material prevents a repetitive criticality even though the safety plug does bounce upward again on the cushion of air in the cylinder.

This sequence results in power and integrated power curves as shown in Figure 24. The total nuclear energy release is about $2.8 \times 10^{6} \mathrm{cal}$ ories or $3.6 \times 10^{17}$ fissions. Since it requires $5.5 \times 10^{5}$ calories to vaporize a kilogram of uranium from room temperature, substantially less than 5 kilograms will be vaporized. A part of the heat goes to melting the remainder of the core.

However, the molten uranium thrown into the pit may burn, adding a significant amount of chemical energy to the excursion. The air contained in the pit and tunnel amounts to some 500 cubic feet containing about 110 gram molecular weights of oxygen. This is sufficient to burn 82 gram atomic weights (about 20 kilograms) of uranium in $\mathrm{U}_{3} \mathrm{O}_{8}$, with the release of approximately $2.3 \times 10^{7}$ calories (burning uranium releases about $2.8 \times 10^{5}$ calories/gram-atom).

Thus, the excursion will result in the release of not more than about $2.5 \times 10^{7}$ calories of which 90 percent is chemical energy. The $500 \mathrm{cu}-$ bic feet of air in the pit and tunnel weigh about $1.5 \times 10^{4}$ grams. The energy of the excursion is sufficient (taking the specific heat of air at constant volume as 0.18 calories $/$ gram $-{ }^{\circ} \mathrm{C}$ ) to raise the temperature of air in the pit to $1230^{\circ} \mathrm{K}$. If this happens nearly instantaneously, the corresponding pres sure is about $37 \mathrm{psig.} \mathrm{This} \mathrm{could} \mathrm{conceivably} \mathrm{impart} \mathrm{a} \mathrm{velocity} \mathrm{as} \mathrm{high} \mathrm{as}$ $50 \mathrm{feet} / \mathrm{second}$ to the manhole cover. Such a velocity would perhaps be sufficient to reach and rupture the roof. However, this is the upper limit on the violence that might be expected. Some leakage will occur around the reactor plugs, but the comparatively high mass loading relative to the surface exposed to the internal pressure makes it unlikely that any significant motion will occur.

More realistically, the burning of the uranium will require a varying time depending on the exposed surface of the molten blobs ejected into the reactor pit and the progressive depletion of oxygen. Since the pit is vented through two 8 inch pipes (intake and exhaust of the pit ventilation system), a high leakage rate combined with a finite rate of heat generation will greatly reduce the overpressure from the maximum estimated above. It appears probable that the building will not rupture, and that a large amount of radioactive material will be ejected into the building through the manhole with a lesser amount conducted to the outside through the ventilating system exhaust (the intake is inside the building).

In summary, the foregoing analysis leads to the conclusion that the excursion hypothesized results in destruction of the reactor, but ruptures 
neither the shield nor the reactor building. There is intense contamination of the pit, tunnel, and reactor building with some material conducted to the outside.

However, to set an upper limit to the hazard to other personnel which might ensue, two extreme cases of radioactive cloud emission have been considered. In the first case, it is postulated that a cloud containing one-half of all fission products escapes from the building at ground level. In the second case, the same cloud is assumed to reach the air through the top of the reactor building at a nominal height of 10 meters.

Table IV summarizes the maximum doses which might be expected should the clouds postulated pass directly over the receptor. The distances of 50 and 100 meters were used as being the round number dis tances to ZPR-III and EBR-I respectively. Holland's nomograph(6) was used to obtain the gamma doses and the beta doses were calculated from the following equation from the same reference.

$$
\begin{aligned}
\operatorname{TID}(\operatorname{Rep})=4.8 \times 10^{16} \frac{\mathrm{Mev} / \mathrm{sec}}{\mathrm{Mw}-\sec } \times(0.64) \mathrm{E}_{\mathrm{r}} \overline{\mathrm{u}}^{0.21} \exp \left(\frac{-\mathrm{h}^{2}}{\mathrm{C}^{2} \mathrm{~d}^{2}-\mathrm{n}}\right) \\
\left.\times\left[\left(6.8 \times 10^{10} \mathrm{Mev} / \mathrm{n}^{3} / \mathrm{r}\right) \times \pi \mathrm{C}^{2} \mathrm{~d}^{(2-\mathrm{n}+1.21)}\right)\right]^{-1}
\end{aligned}
$$

where

$$
\begin{aligned}
\mathrm{E}_{\mathbf{r}}= & \text { Excursion energy release (Mw-sec) } \\
\mathrm{d}= & \text { Downwind distance (meters) } \\
\mathrm{h}= & \text { Cloud height, i.e. equivalent point source height from nomogran } \\
& \text { (meters) } \\
\overrightarrow{\mathrm{u}}= & \text { Wind velocity (meters/second) } \\
\mathrm{n}= & \text { Sutton stability parameter } \\
\mathrm{C}= & \text { generalized diffusion coefficient }
\end{aligned}
$$

The following values of the atmospheric parameters were chosen as reasonably typical of the area and were used in obtaining both gamma and beta doses.

$$
\begin{aligned}
& \mathrm{n}=0.25 \\
& \mathrm{C}=0.20
\end{aligned}
$$

Since the reactor is to be operated only at low power, all fission products are assumed to originate in the excursion itself.

The following factors ameliorate the above estimates: 
1. Except for an occasional guard on patrol and part-time lawn labor, all personnel within $3 \frac{1}{2}$ miles (the distance to Central Facilities) are either working in the EBR, ZPR, or ancillary buildings, or are transient on the highway $1 \frac{3}{4}$ miles away. This protection would virtually eliminate any beta dose and considerably reduce the effect of gamma radiation.

2. The wind pattern (see Figure 18) would carry a radiation cloud toward EBR and $Z P R$ less than 10 percent of the time.

\section{Table IV}

\section{PROBABLE MAXIMUM DOSES FROM RADIATION CLOUD}

Ground Level Cloud

\begin{tabular}{|c|c|c|c|}
\hline Wind $(\mathrm{M} / \mathrm{s})$ & & $\begin{array}{l}50 \text { Meters } \\
\text { Downwind } \\
\end{array}$ & $\begin{array}{l}100 \text { Meters } \\
\text { Downwind }\end{array}$ \\
\hline 2 & $\begin{array}{l}\text { Gamma } \\
\text { Beta }\end{array}$ & $\begin{array}{c}15 \mathrm{r} \\
180 \mathrm{Rep}^{1}\end{array}$ & $\begin{array}{c}3 \mathrm{r} \\
23 \mathrm{Rep}^{1}\end{array}$ \\
\hline 8 & $\begin{array}{l}\text { Gamma } \\
\text { Beta }\end{array}$ & $\begin{array}{c}12 \mathrm{r} \\
240 \mathrm{Rep}^{1}\end{array}$ & $\begin{aligned} & 3 \mathrm{r} \\
31 & \operatorname{Rep}^{1}\end{aligned}$ \\
\hline & \multicolumn{3}{|c|}{ Cloud Height 10 Meters } \\
\hline 2 & $\begin{array}{l}\text { Gamma } \\
\text { Beta }\end{array}$ & $\begin{array}{c}5 \frac{1}{2} r \\
42 \operatorname{Rep}^{1}\end{array}$ & $\begin{array}{l}2 \frac{1}{2} \mathrm{r} \\
19 \mathrm{Rep}^{1}\end{array}$ \\
\hline 8 & $\begin{array}{l}\text { Gamma } \\
\text { Beta }\end{array}$ & $\begin{array}{c}4 \frac{1}{2} \mathrm{r} \\
56 \mathrm{Rep}^{1}\end{array}$ & $\begin{array}{c}2 \frac{1}{2} \mathrm{r} \\
25 \mathrm{Rep}^{1}\end{array}$ \\
\hline
\end{tabular}

${ }^{1}$ These are the bar skin beta doses. When the protection of ordinary clothing is considered, they may be too large by as much as an order of magnitude. 


\section{APPENDIX II}

\section{ERROR OR MISHAP IN OPERATION}

A distraction or sudden disability of the operator while running in the control rod might lead to the control rod's being fully inserted. As sume that the maximum reactivity the reactor might ever require could be just that necessary to furnish a reasonable period at the top of the permissible temperature range; this would amount to roughly $.0014 \Delta \mathrm{k} / \mathrm{k}$ to furnish the period and maximum of $.0009 \Delta \mathrm{k} / \mathrm{k}$ to override the temperature coefficient, or a total of about 100 inhours $\left(2.3 \times 10^{-3} \Delta \mathrm{k} / \mathrm{k}\right)$ above room temperature delayed critical. This corresponds to an initial period of 15 seconds.

In the worst case of the above type, the reactor would go up on a period of 15 seconds provided that the period meter tripsettings permitted such a short period or that both period meters malfunctioned. If there is joint failure of temperature and both power level trips, the reactor would increase in power until heating of the reactor reduced the reactivity below unity after which it would stabilize at an average core temperature of about $20+\frac{2.3 \times 10^{-3}}{9.4 \times 10^{-6}}=265^{\circ} \mathrm{C}$ and a power level just equal to the equilibrium heat loss for the above temperature. This temperature corresponds to a power level of about 3600 watts based on the fact that in the iron mockup the core, 1000 watts gave a rise of $67^{\circ} \mathrm{C}$ average core temperature over ambient. Maximum dose rate to operating personnel is $27 \mathrm{mr}$ per hour and no damage is done in the reactor.

\section{$\underline{\text { Poor Coordination Between Experimenter and Operator }}$}

Assume that the Chief Physicist has approved an experiment involving irradiation of foils in the glory hole and that the experimenter is positioning the foils by means of a wooden rod which just fits the hole. If, while the reactor is coming up on a period, the rod is inadvertently inserted so as to completely fill the section of the glory hole lying in the core, an incident might occur because of the reactivity effect of the hydrogenous material. If the wood is assumed to have a density of 0.65 and an approximate chemical formula of $\mathrm{CH}_{2} \mathrm{O}$, the reactivity effect of the rod is $2.0 \times 10^{-3} \Delta \mathrm{k} / \mathrm{k}$ based on substitution data in Topsy.

If the original period were 15 seconds corresponding to a reactivity of $2.3 \times 10^{-3} \Delta \mathrm{k} / \mathrm{k}$, the total reactivity would then be $4.3 \times 10^{-3} \Delta \mathrm{k} / \mathrm{k}$. This gives an initial period of about $2 \frac{1}{2}$ seconds which becomes longer as the reactor heats up. Provided both period meter scrams, both power level scrams, and the high temperature scram all fail, the temperature rises 
until $\mathrm{k}$ is reduced to unity. This would be at a temperature of about $20+\frac{4.3 \times 10^{-3}}{9.4 \times 10^{-6}}=480^{\circ} \mathrm{C}$. The equilibrium power level corresponding to this temperature is about 7000 watts, if the air circulation is maintained. If not, then the ultimate power level is something much less. No serious damage to the reactor is anticipated and maximum radiation exposure to personnel is about $53 \mathrm{mr}$ per hour. 


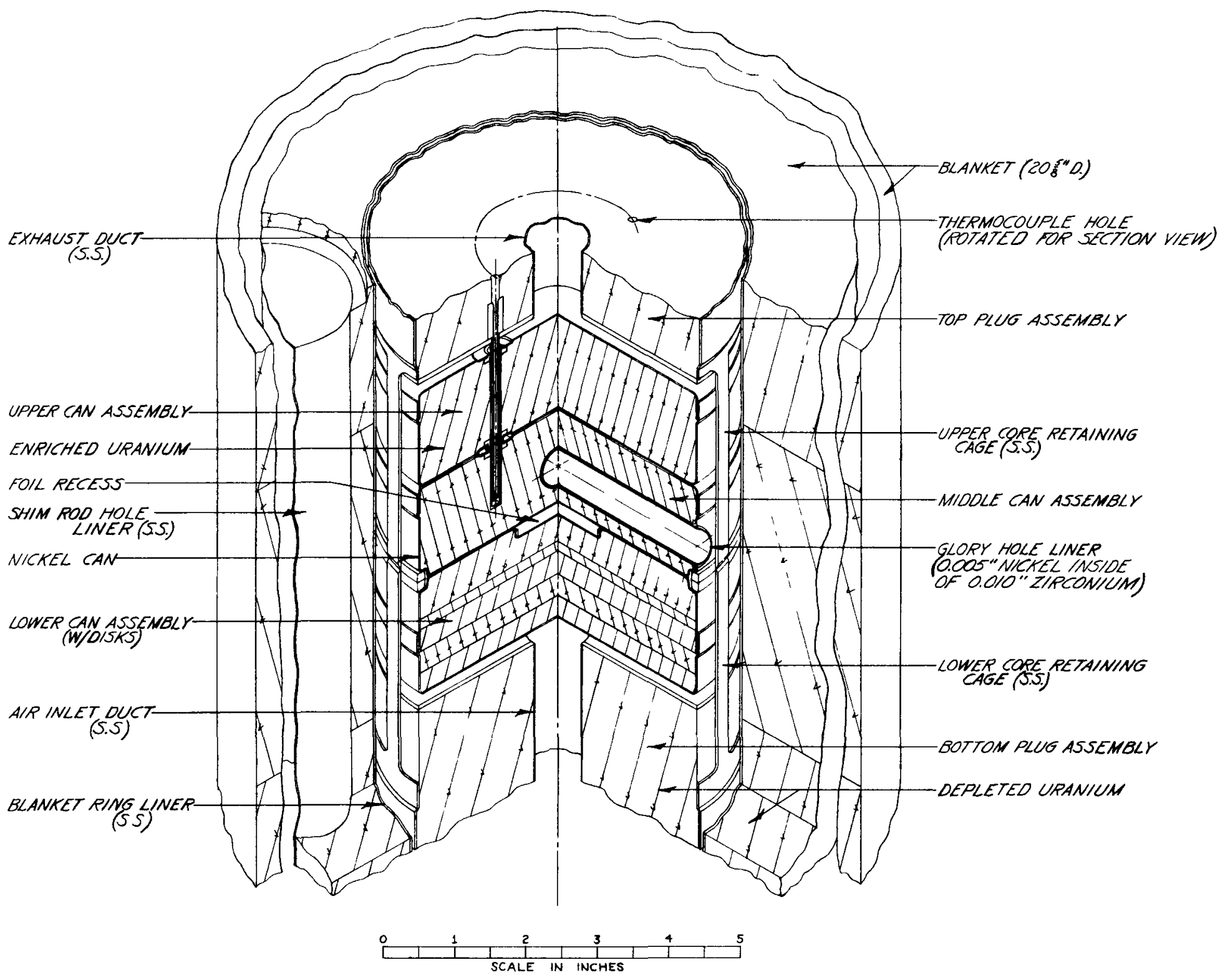

AFSR CORE ASSEMBLY

FIG. 1 


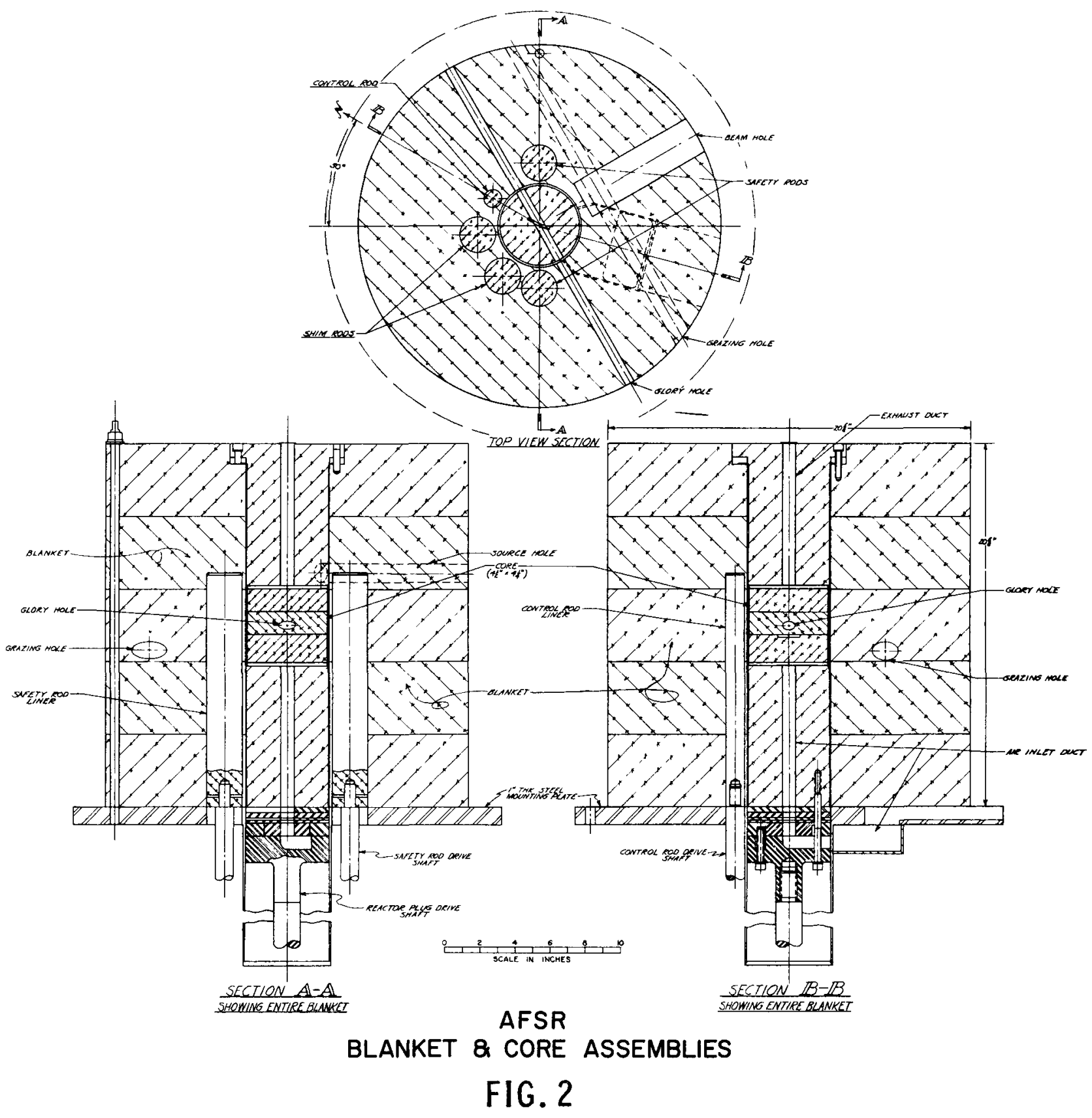




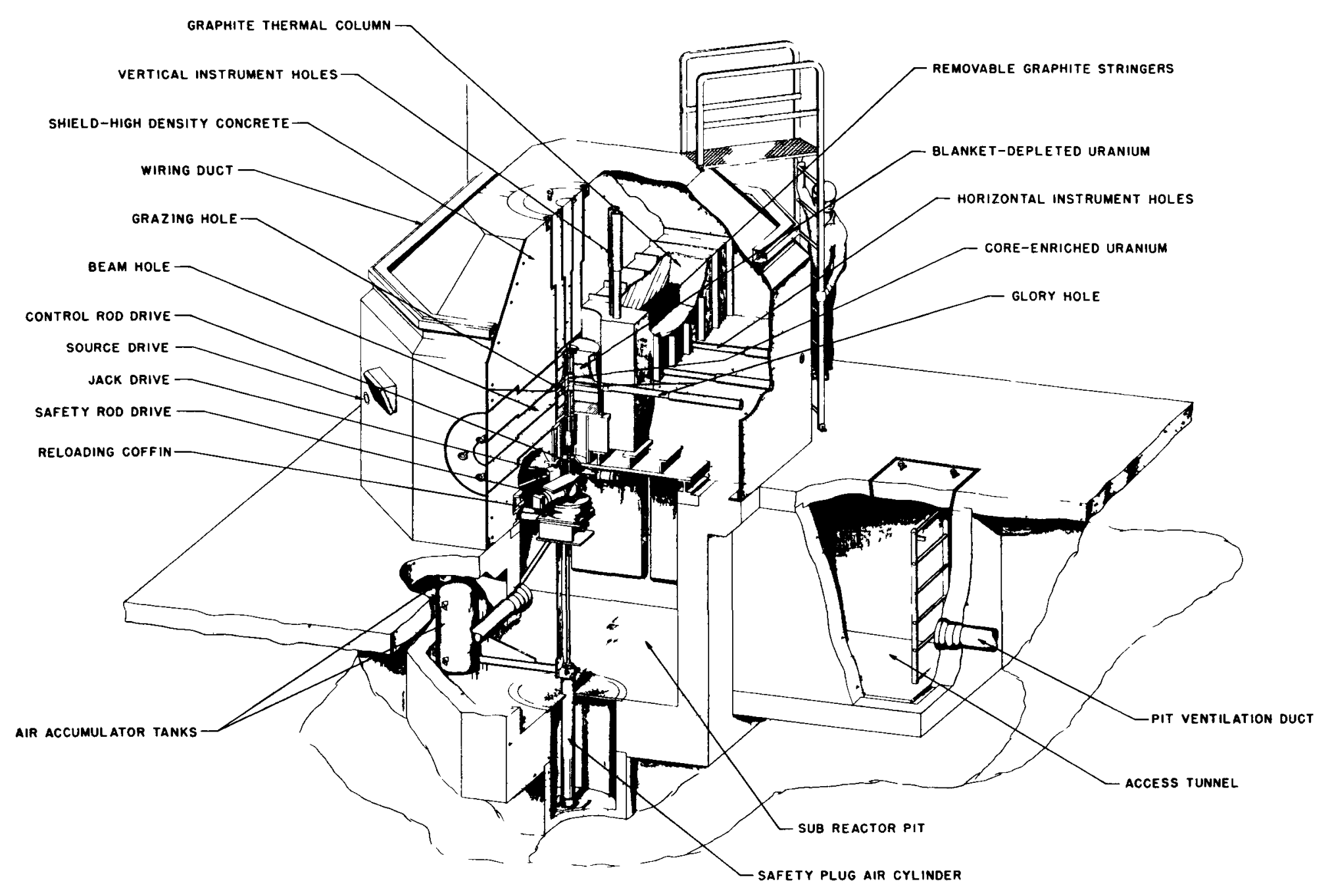

ARGONNE FAST SOURCE REACTOR

FIG. 3 


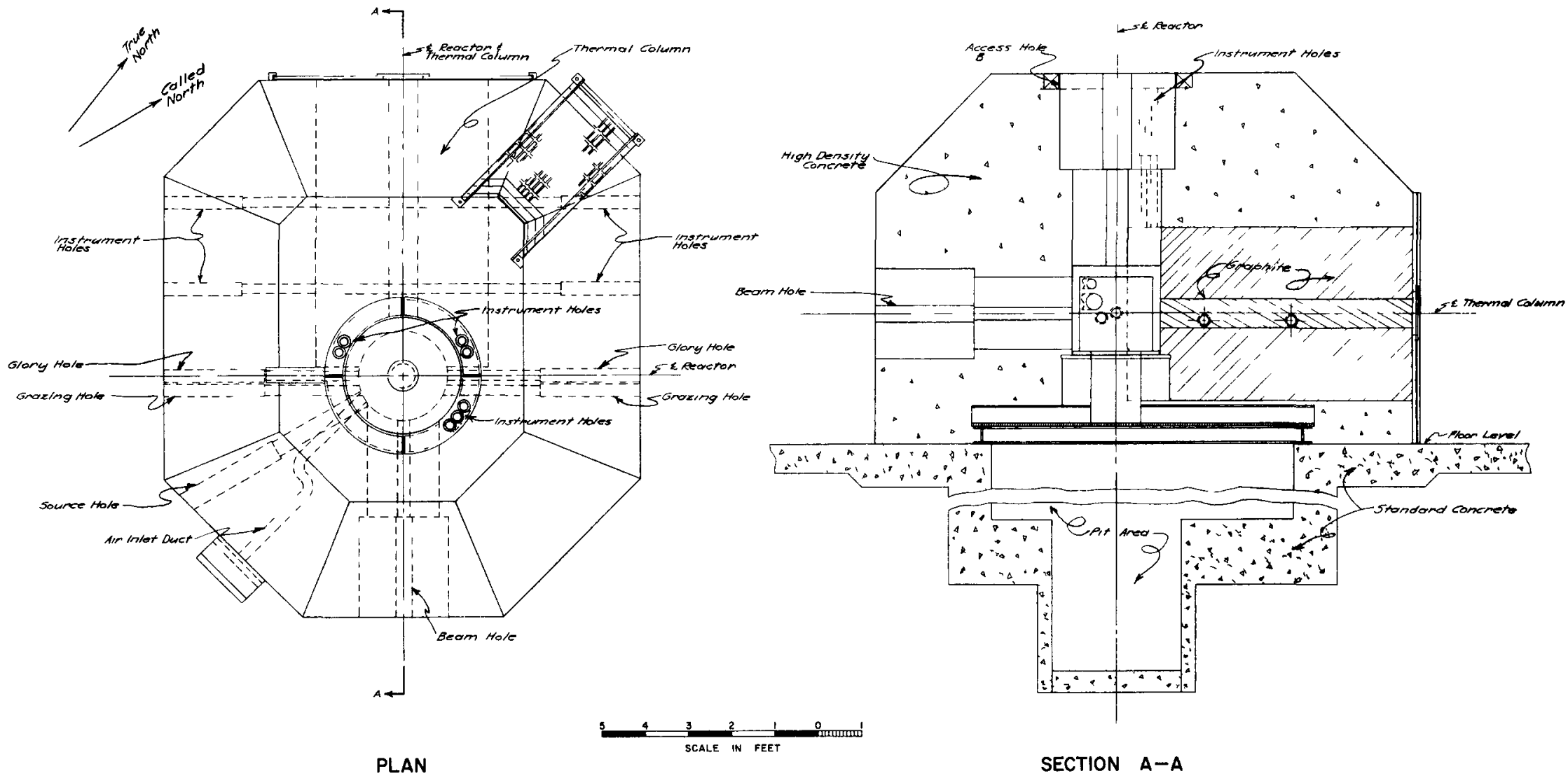

REACTOR \& THERMAL COLUMN

FIG. 4 


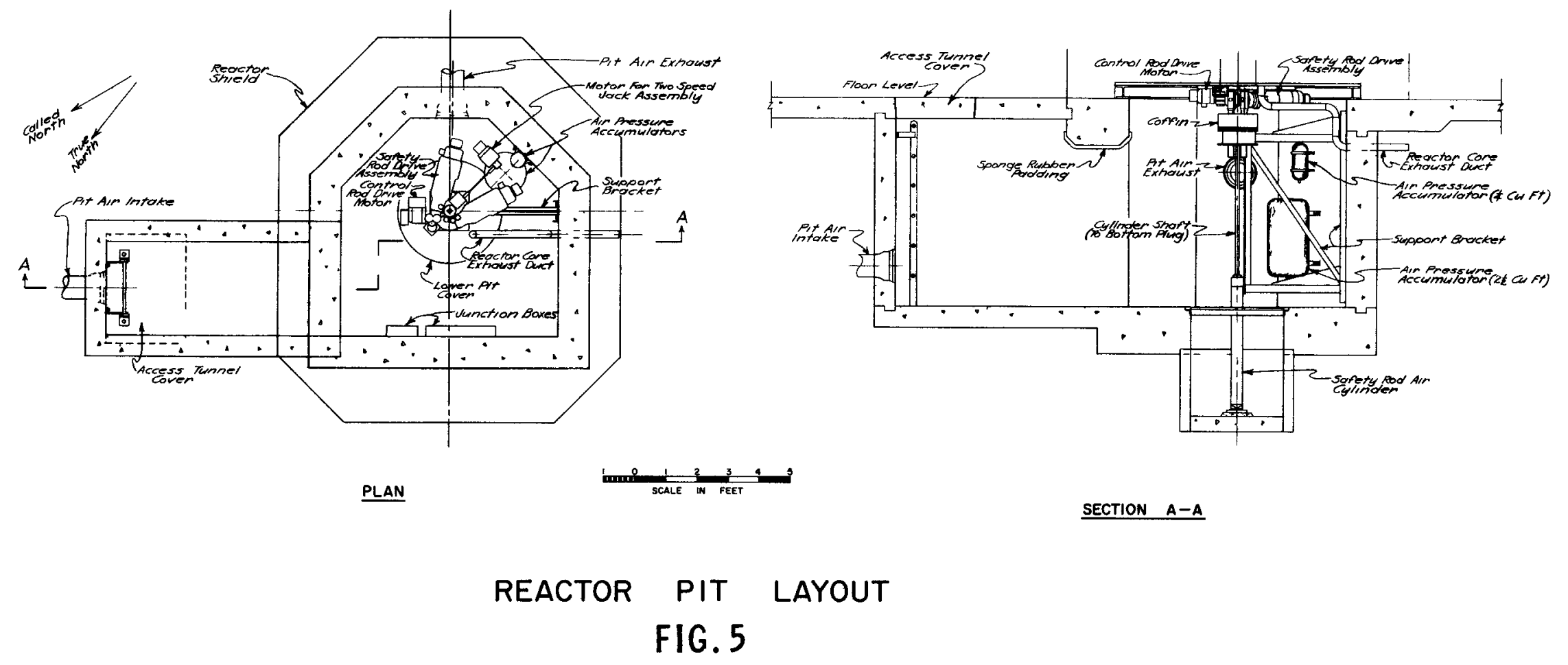




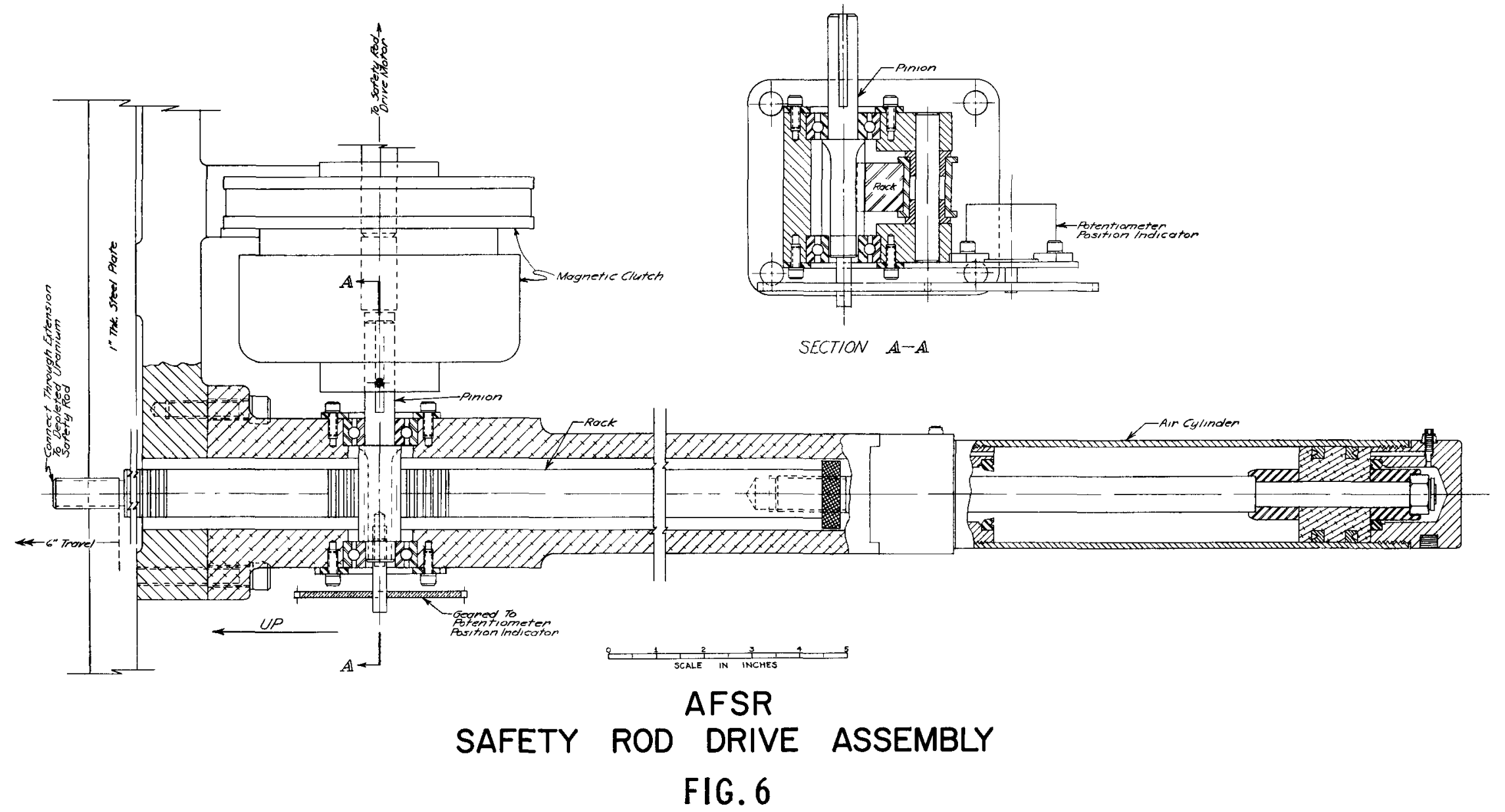




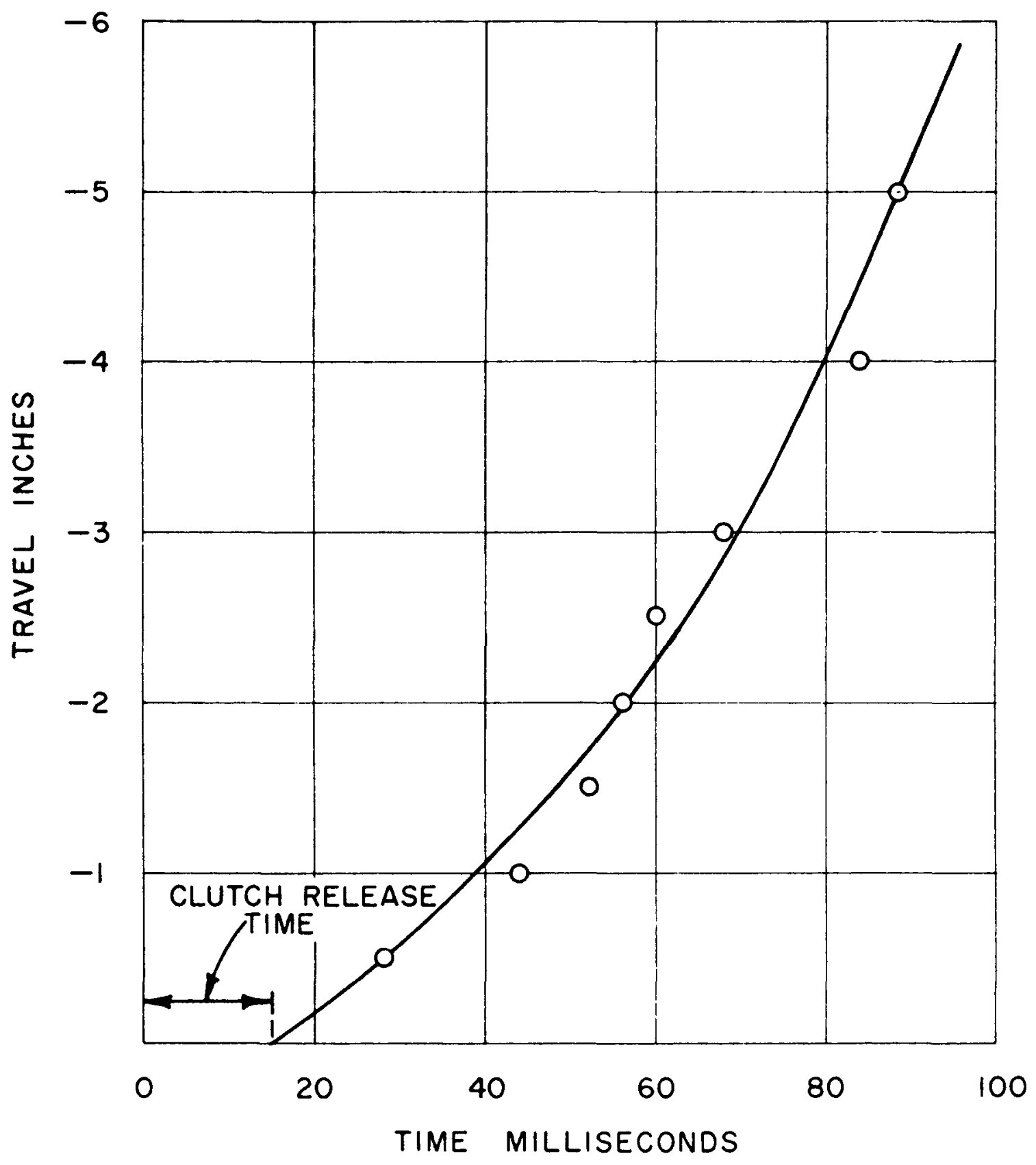

AFSR SAFETY ROD PERFORMANCE CURVE SCRAM PRESSURE $=130 \mathrm{psig}$ SCRAM SIGNAL $=0$ TIME

FIG. 7 


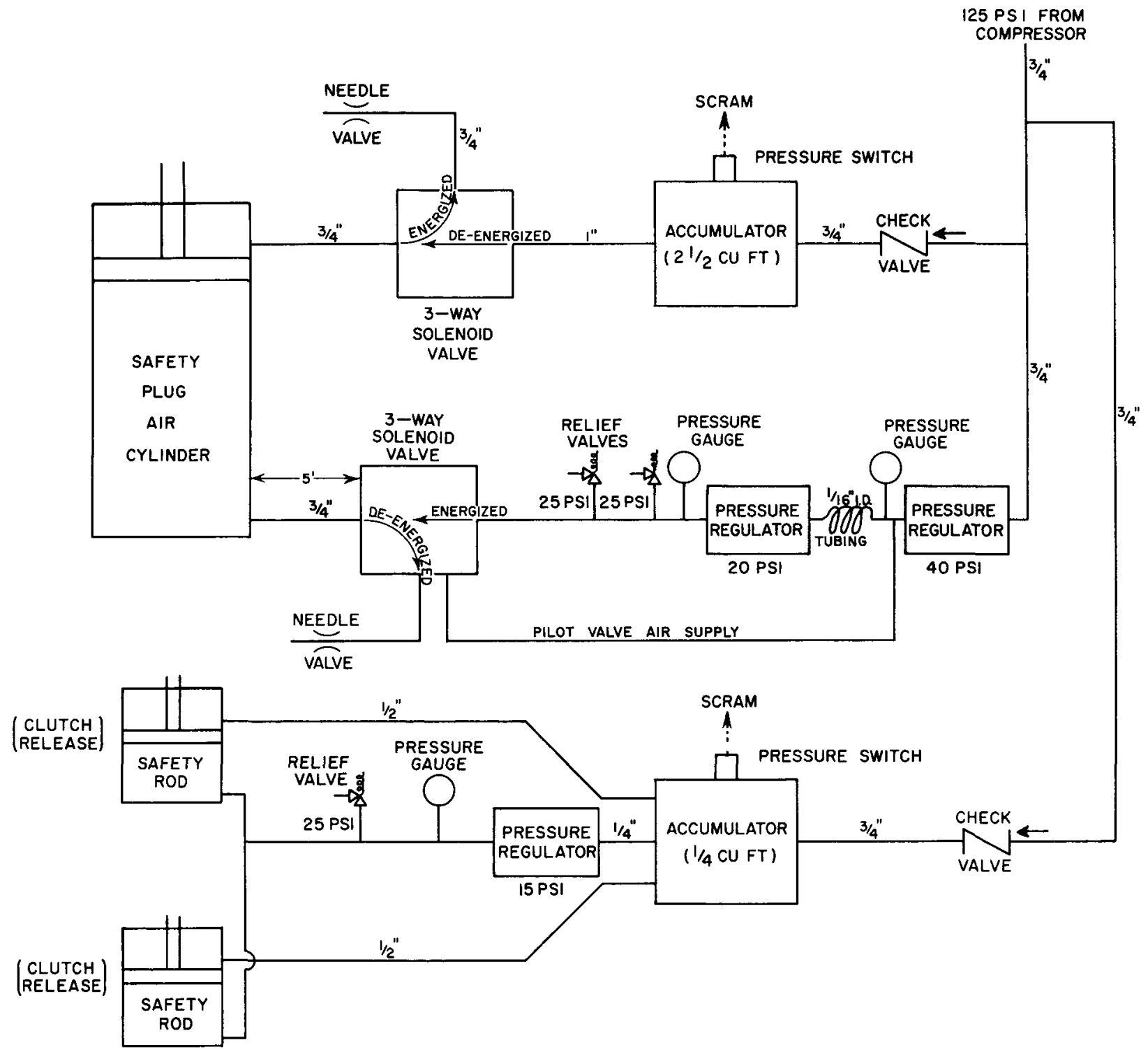

AFSR PNEUMATIC SYSTEM

FIG. 8 


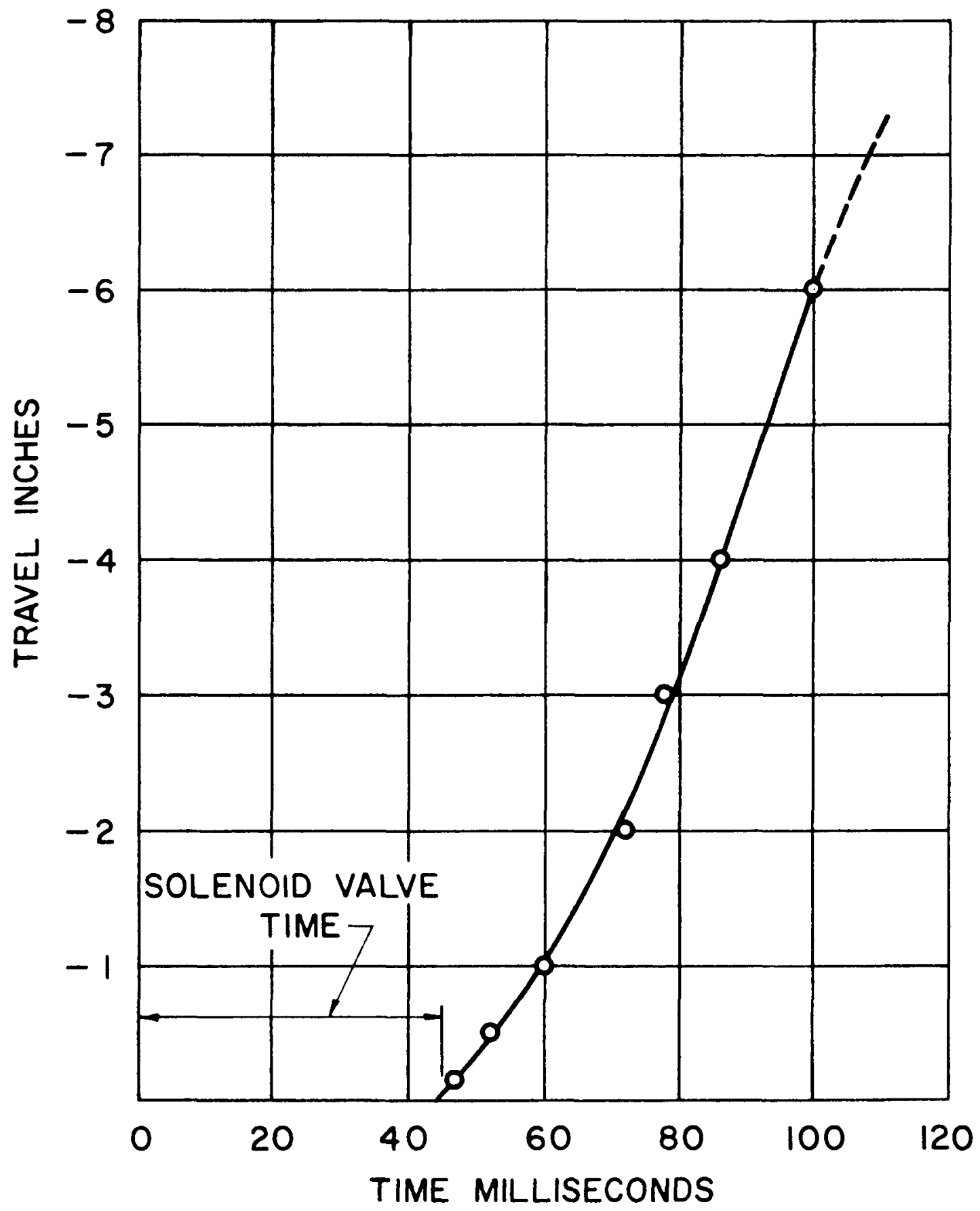

AFSR SAFETY PLUG PERFORMANCE CURVE SCRAM PRESSURE $=125 \mathrm{psig}$ SCRAM SIGNAL $=0$ Time

FIG. $8 \mathrm{a}$ 


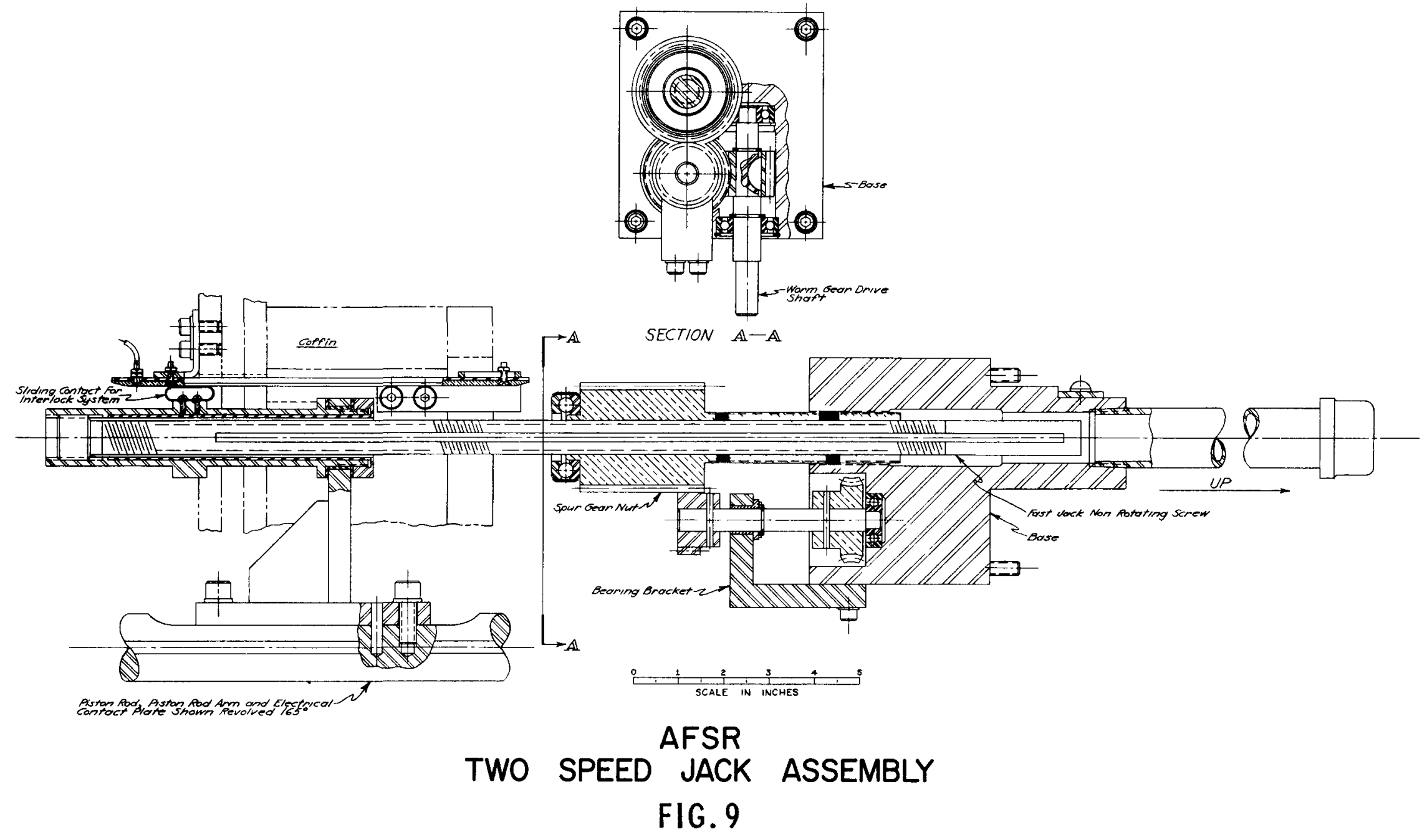




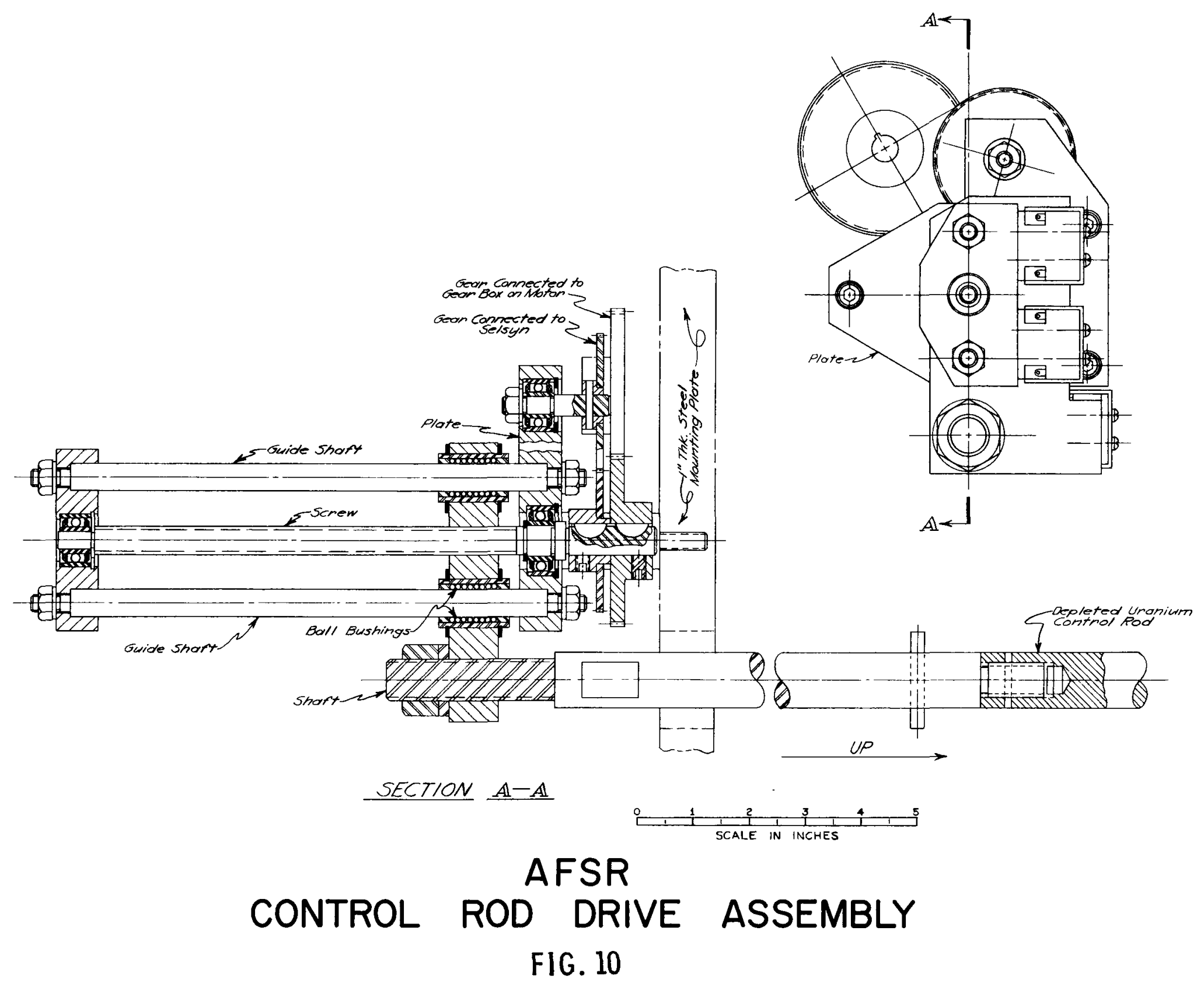




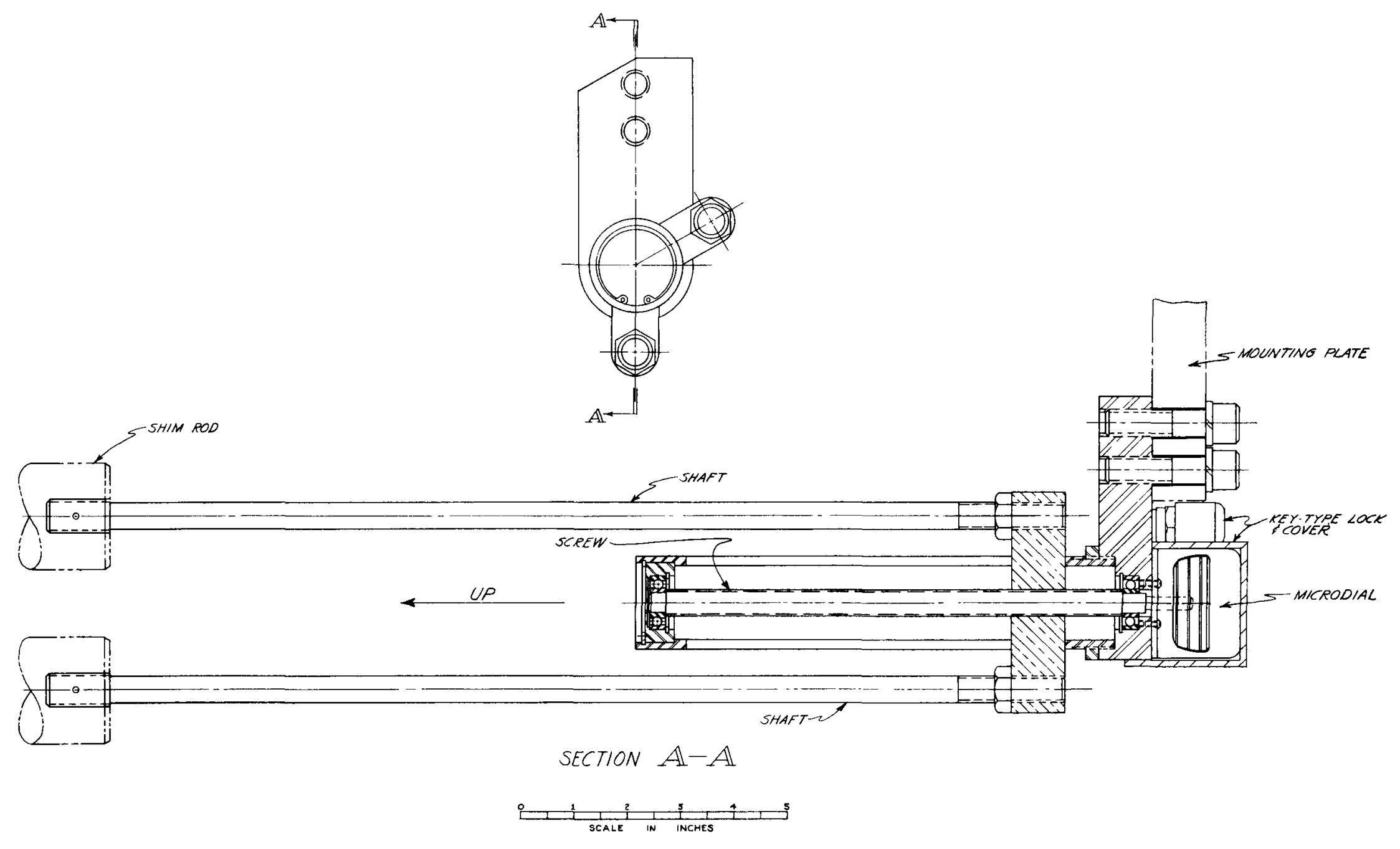

AFSR SHIM ROD ACTUATOR ASSEMBLY

FIG. 11 


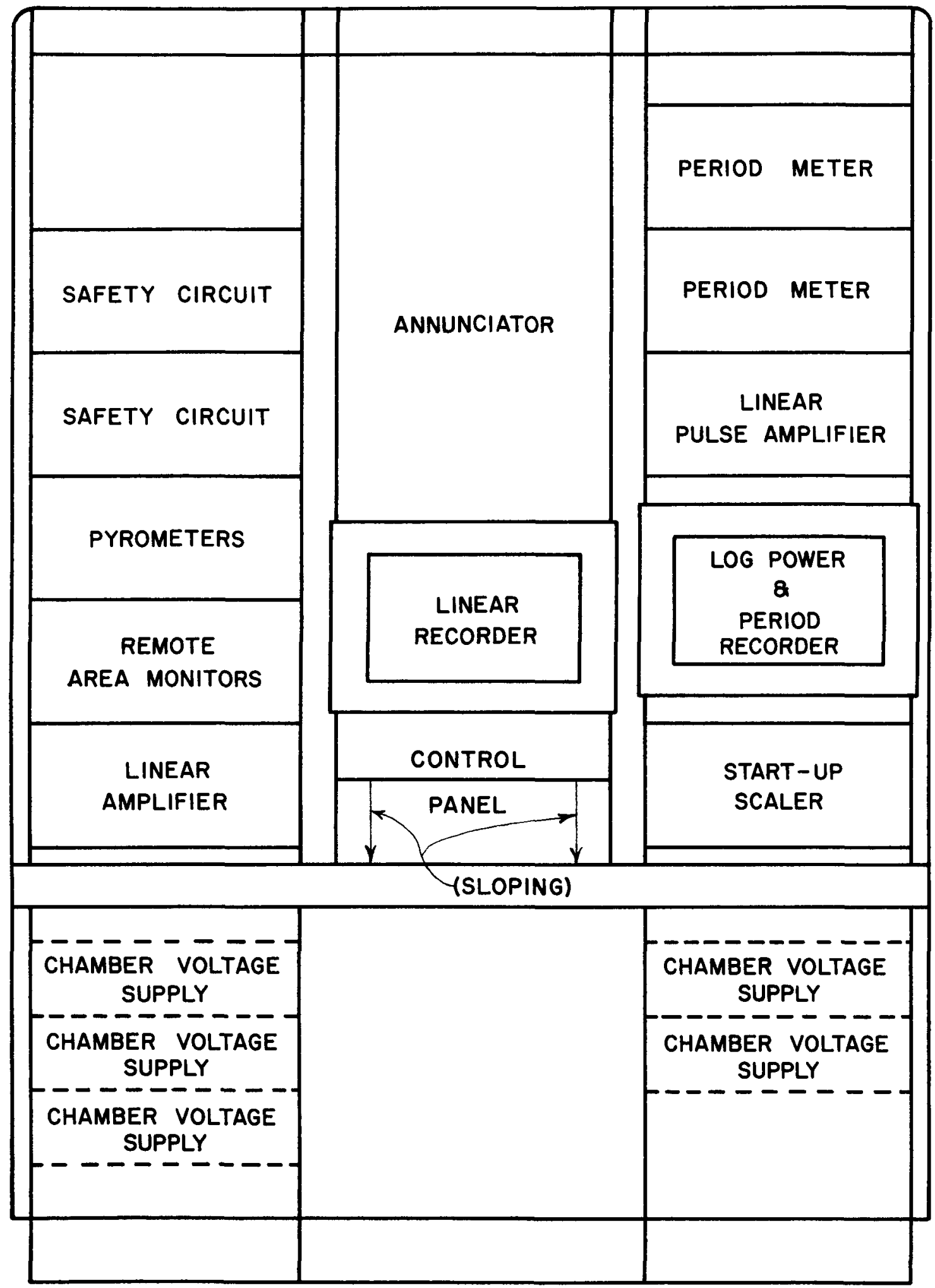

AFSR CONTROL CONSOLE

FIG. 12 


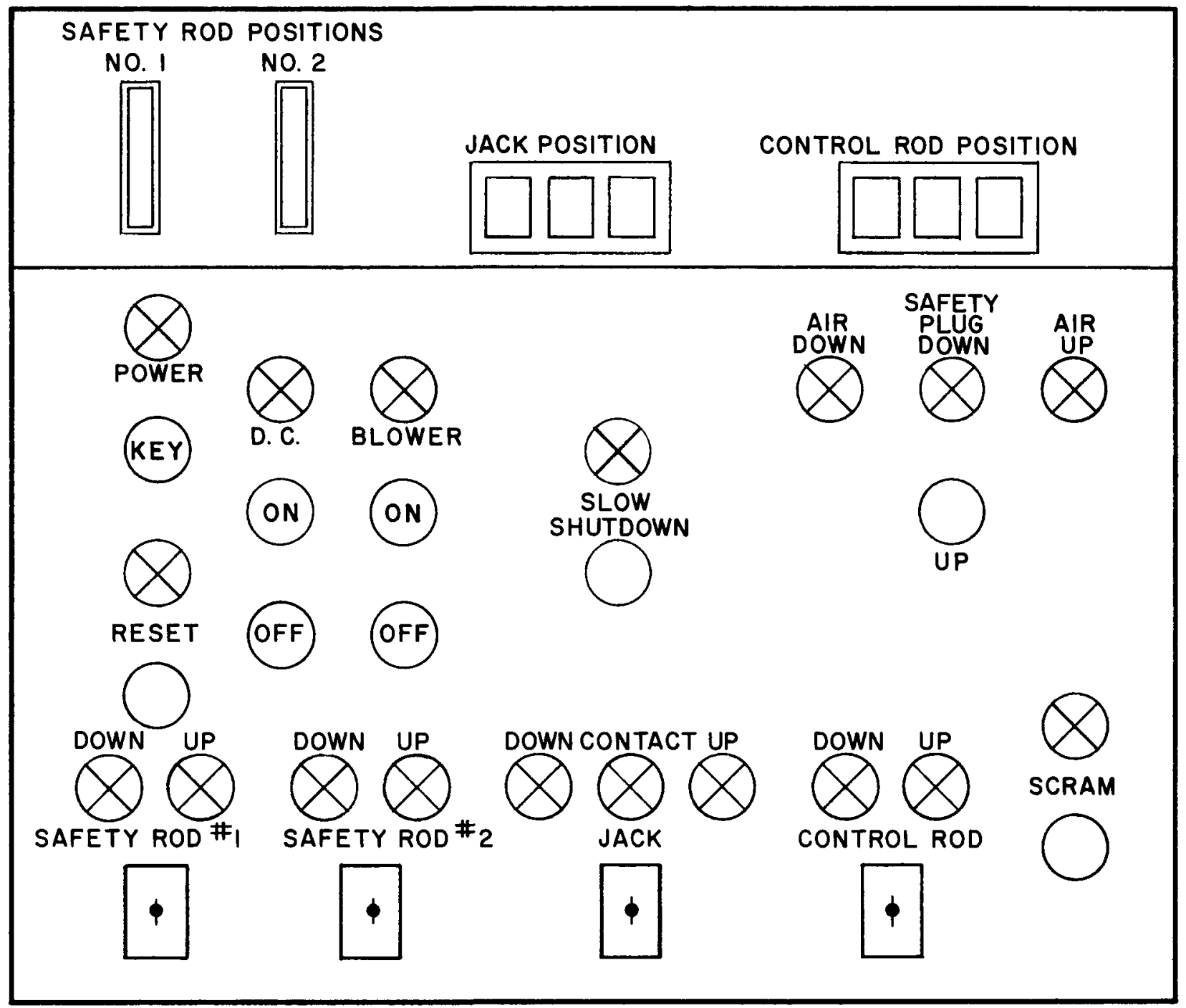

AFSR CONTROL PANEL

FIG. 13 

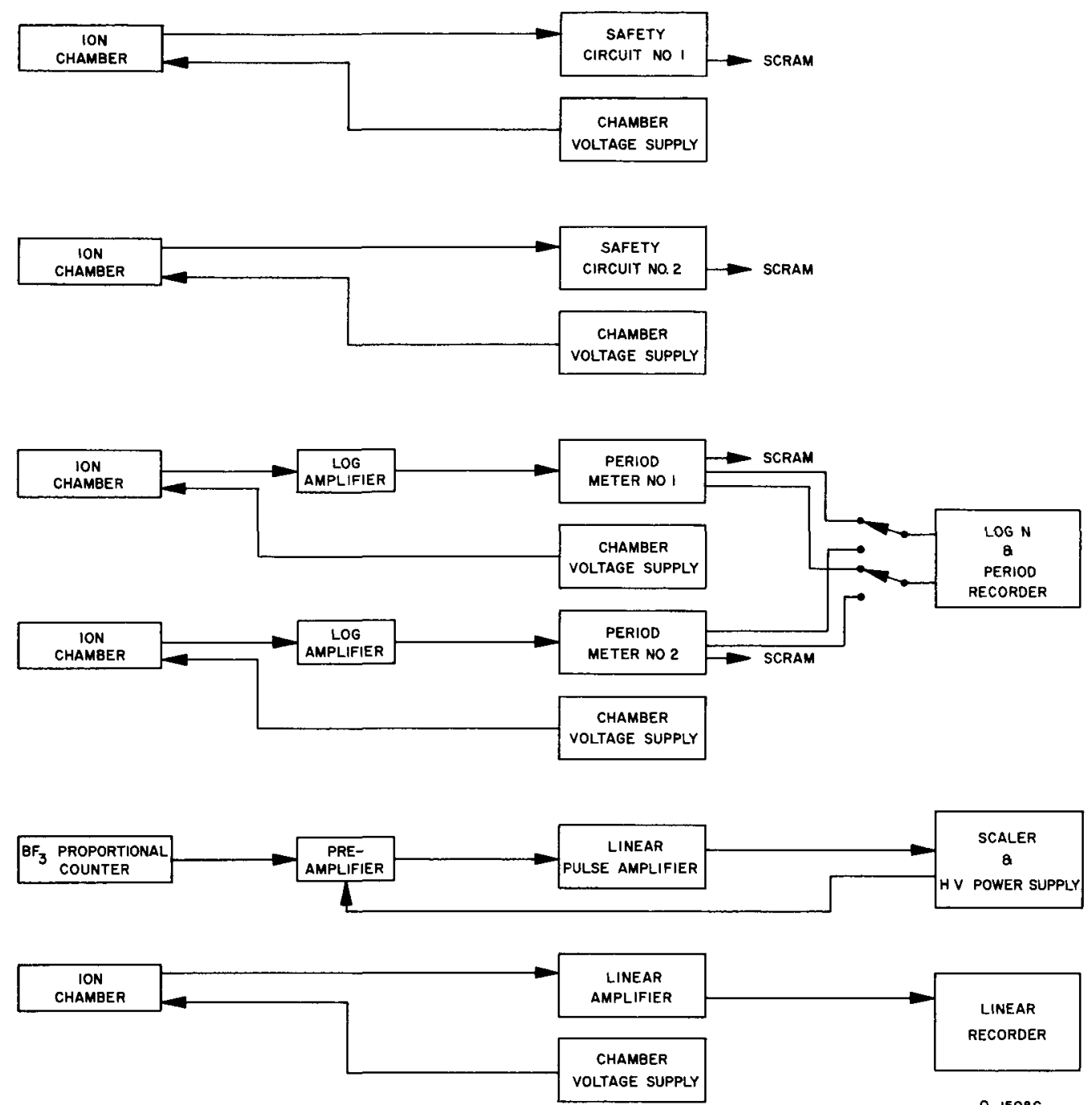

$0-150^{\circ} \mathrm{C}$ CONTACT PYROMETER

FUEL TEMPERATURE THERMOCOUPLE

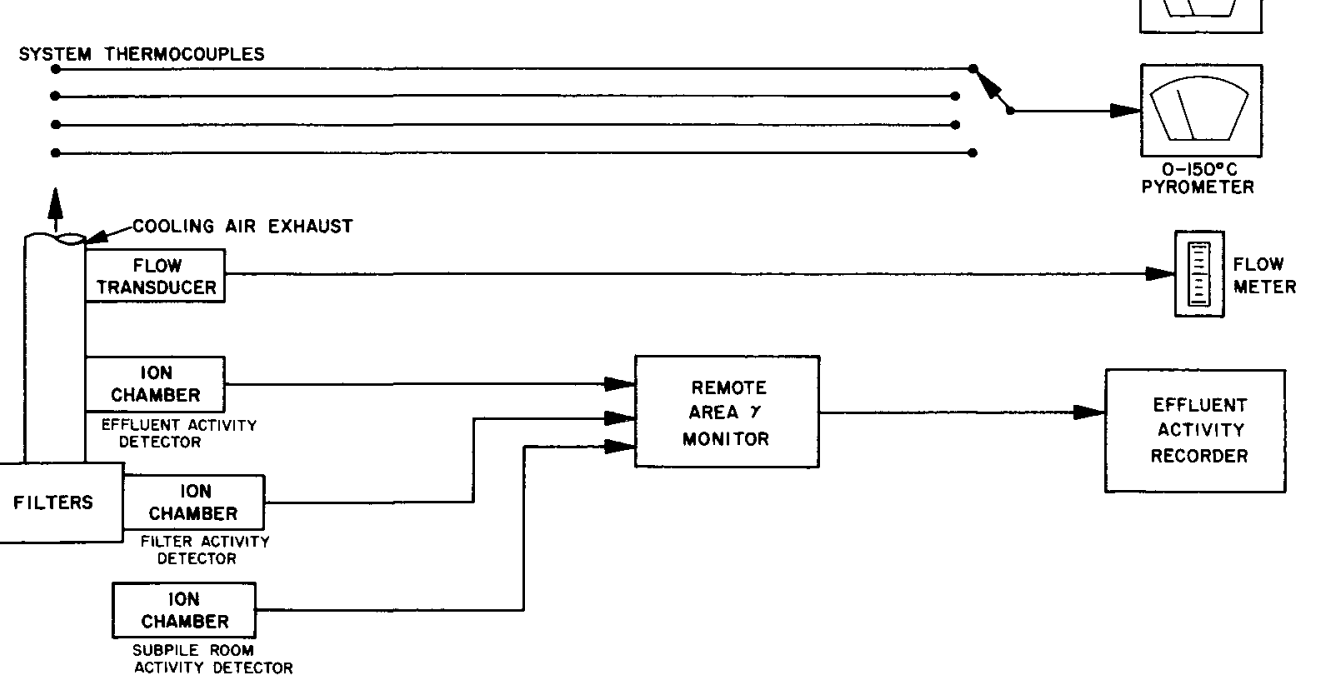

AFSR INSTRUMENTATION

FIG. 14 


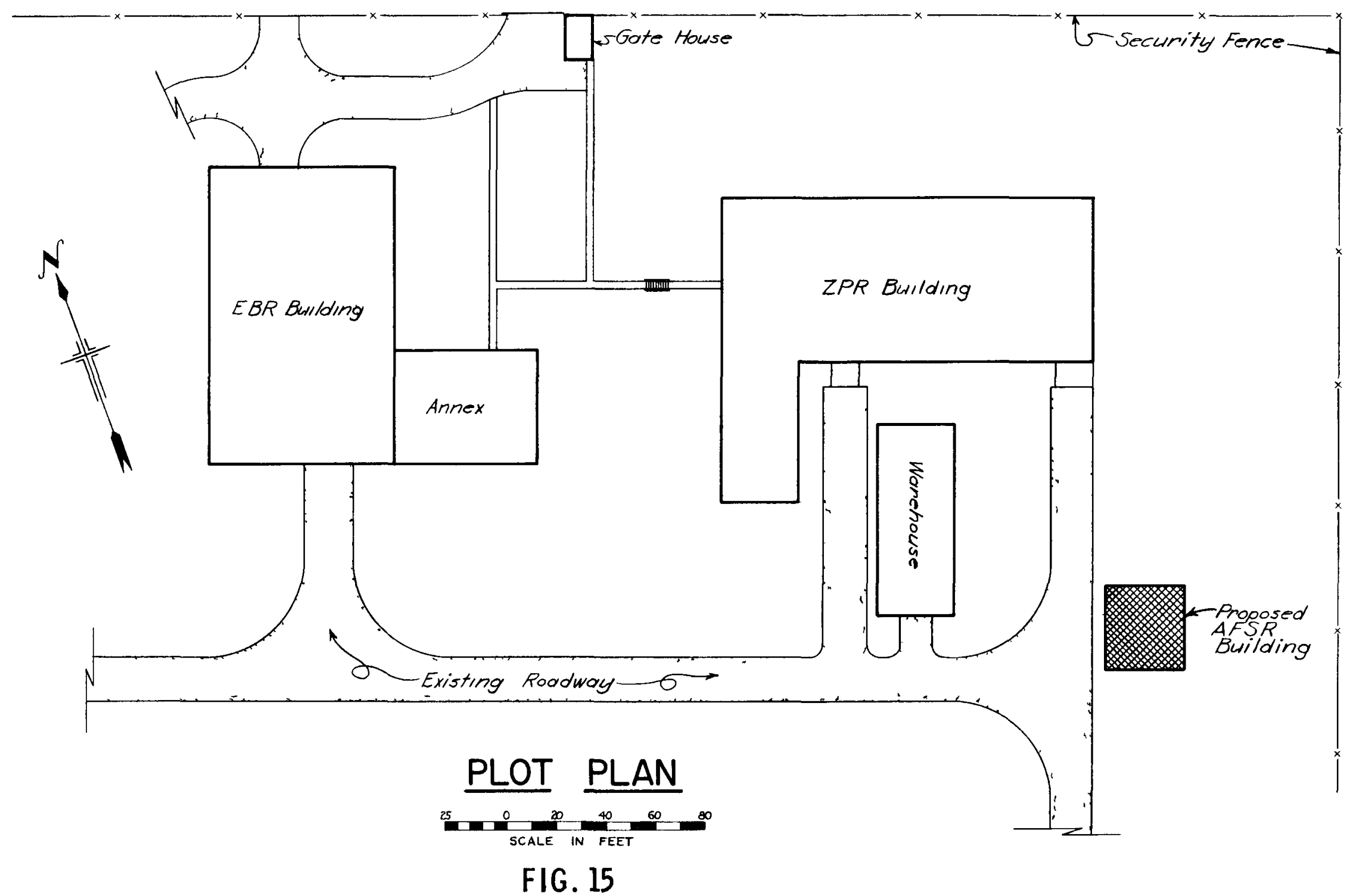




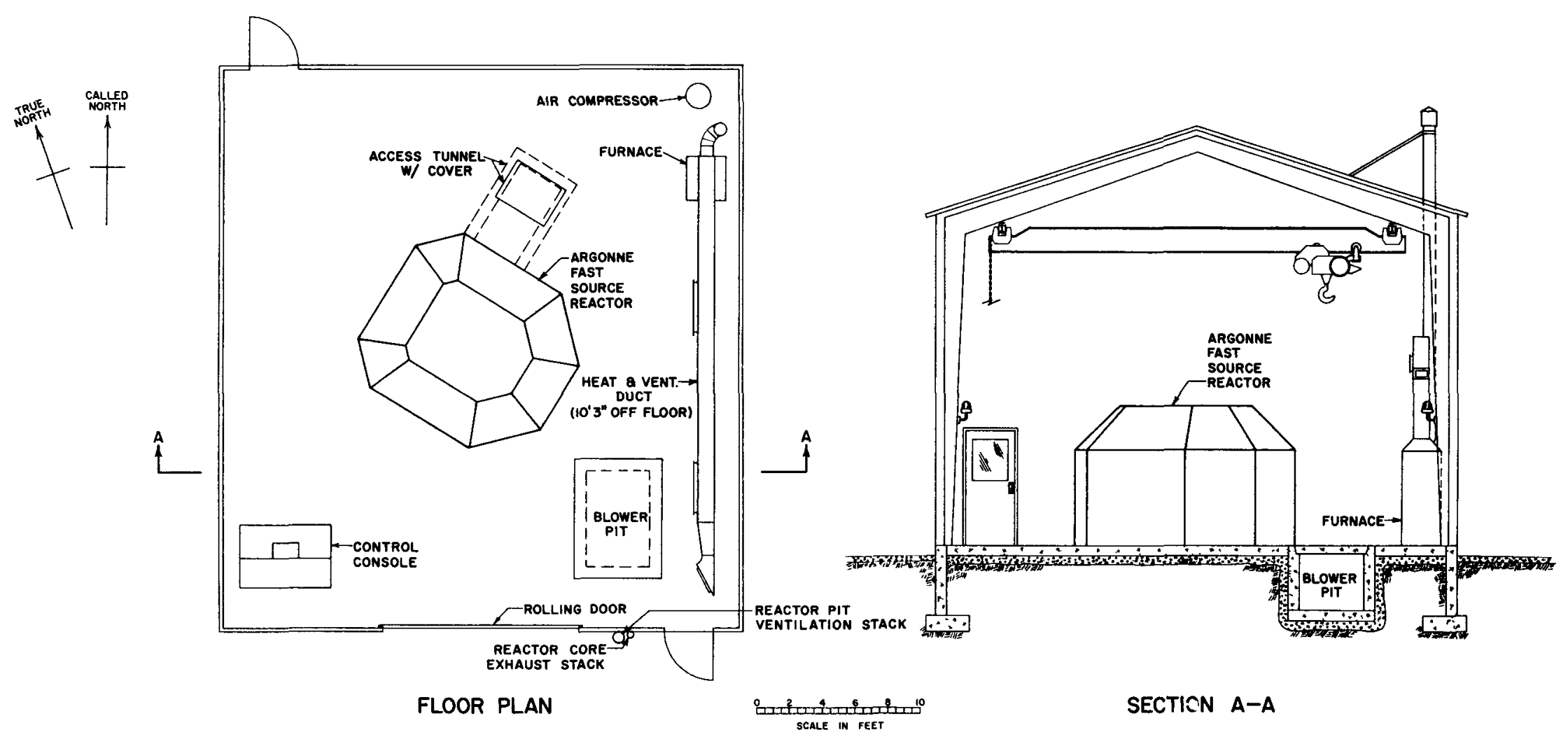

REACTOR BLDG. LAYOUT

FIG. 16 


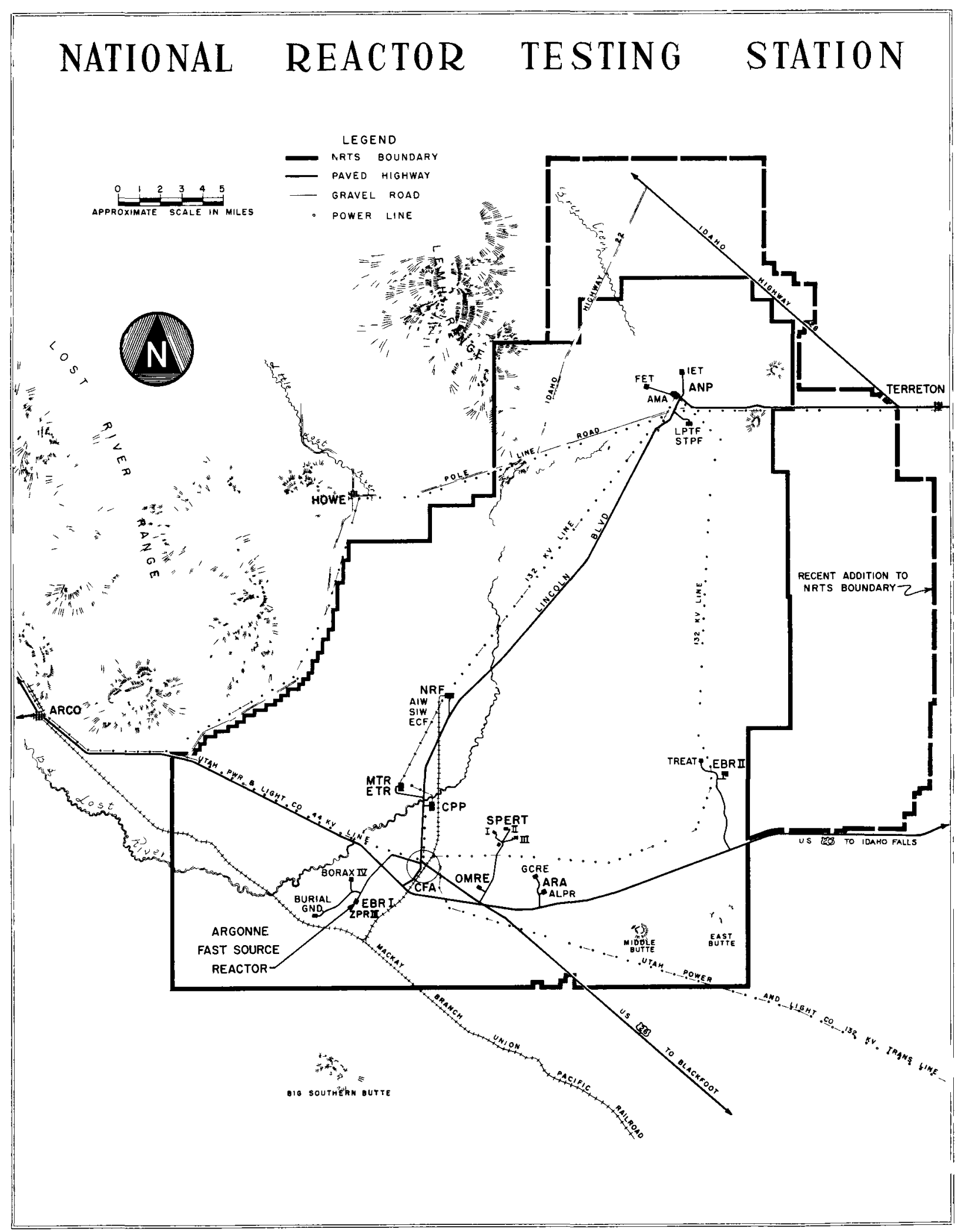

FIG. 17 


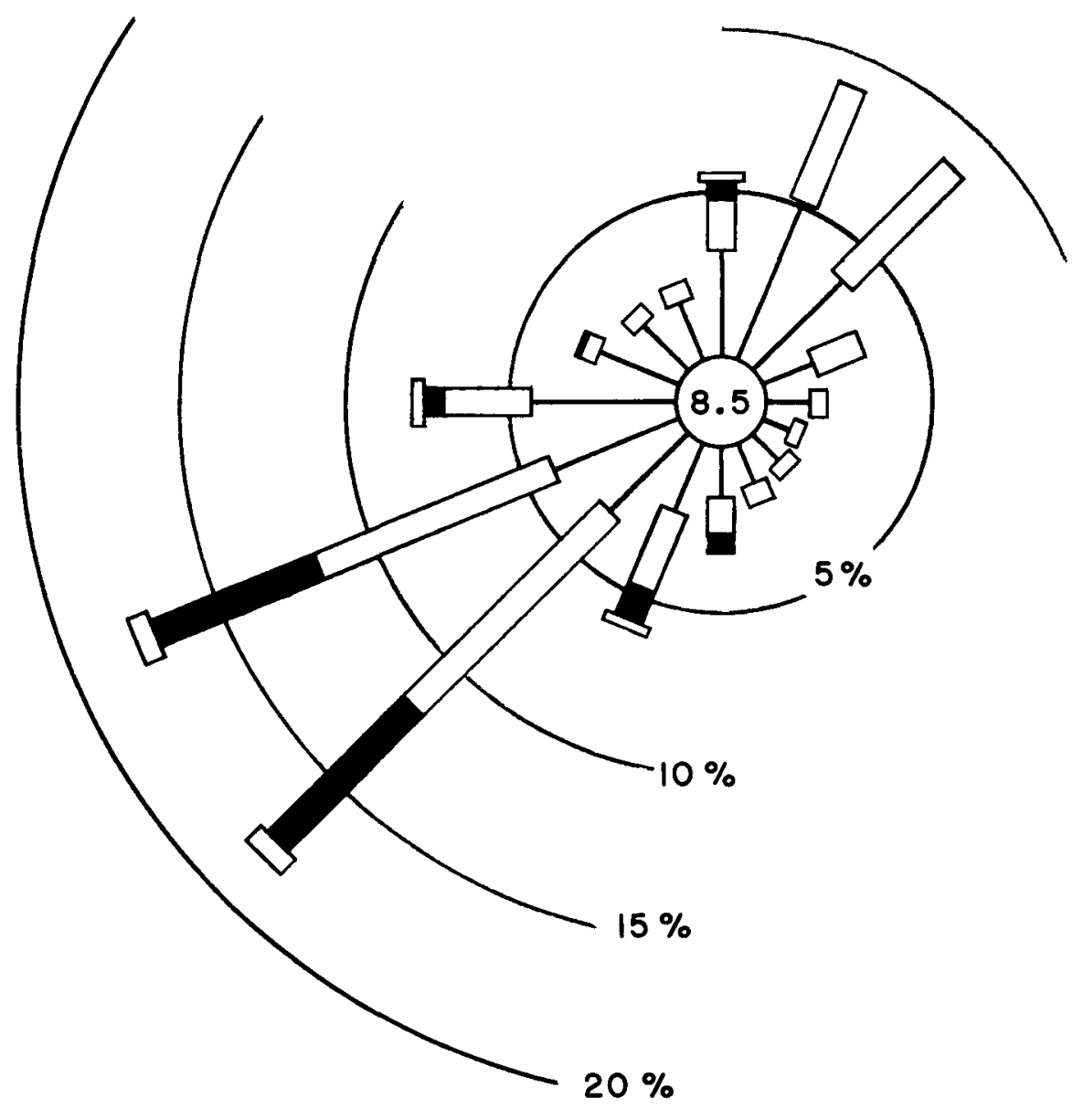

56,948 TOTAL HOURS

$\%$ CALM WIND SPEED MPH $71-5,6-1516-30 \geq 30$

$\%$ FREQUENCY

CENTRAL FACILITIES 20 FOOT LEVEL WIND ROSE 1950 THROUGH 1956

FIG. 18 


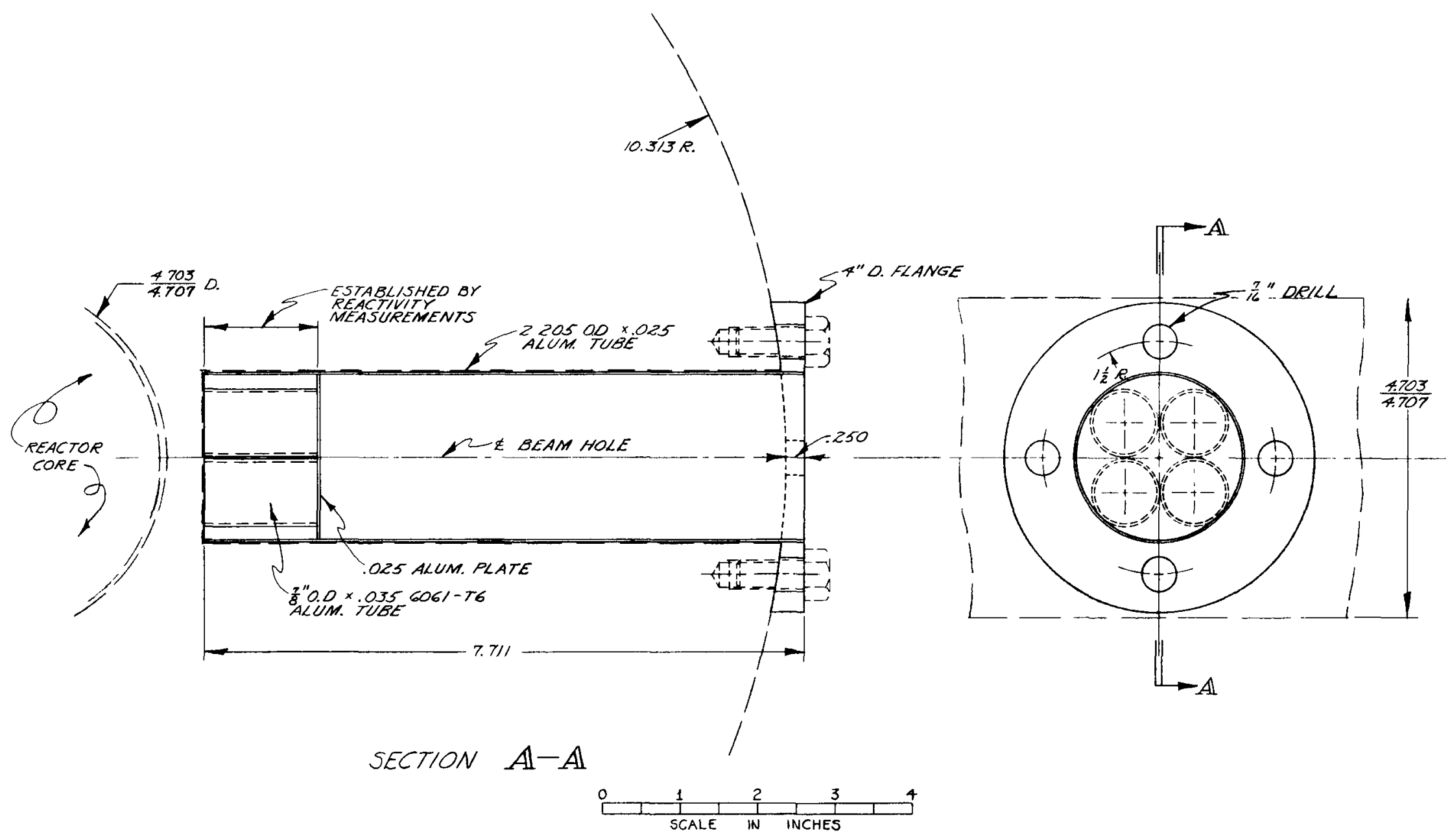

AFSR BEAM HOLE LINER

FIG. 19 


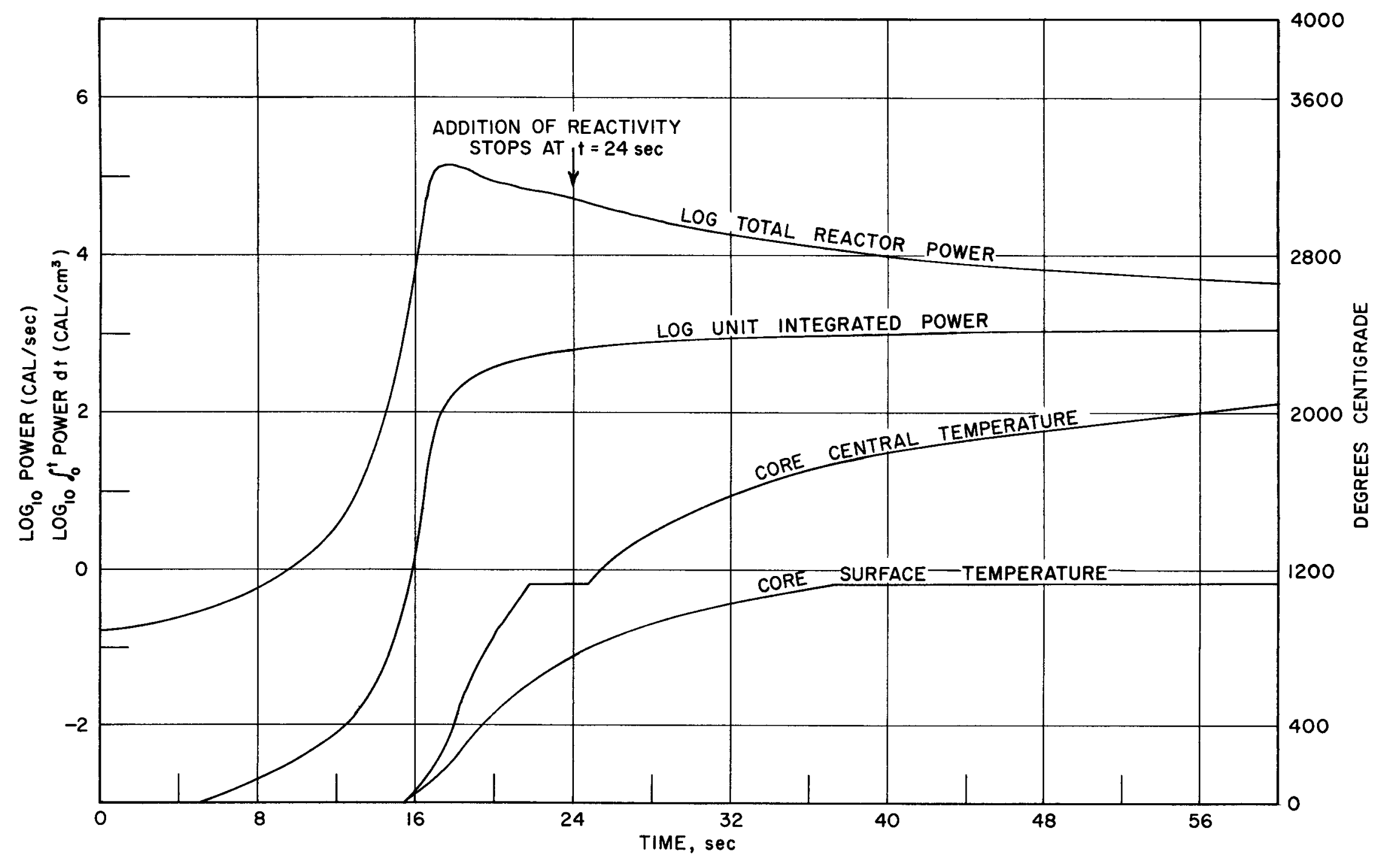

Predicted behavior of AFSR going critical 0.1 inch from fully as sembled position at a rate of $0.0004 \Delta \mathrm{k} / \mathrm{k}$ per second.

FIG. 20 


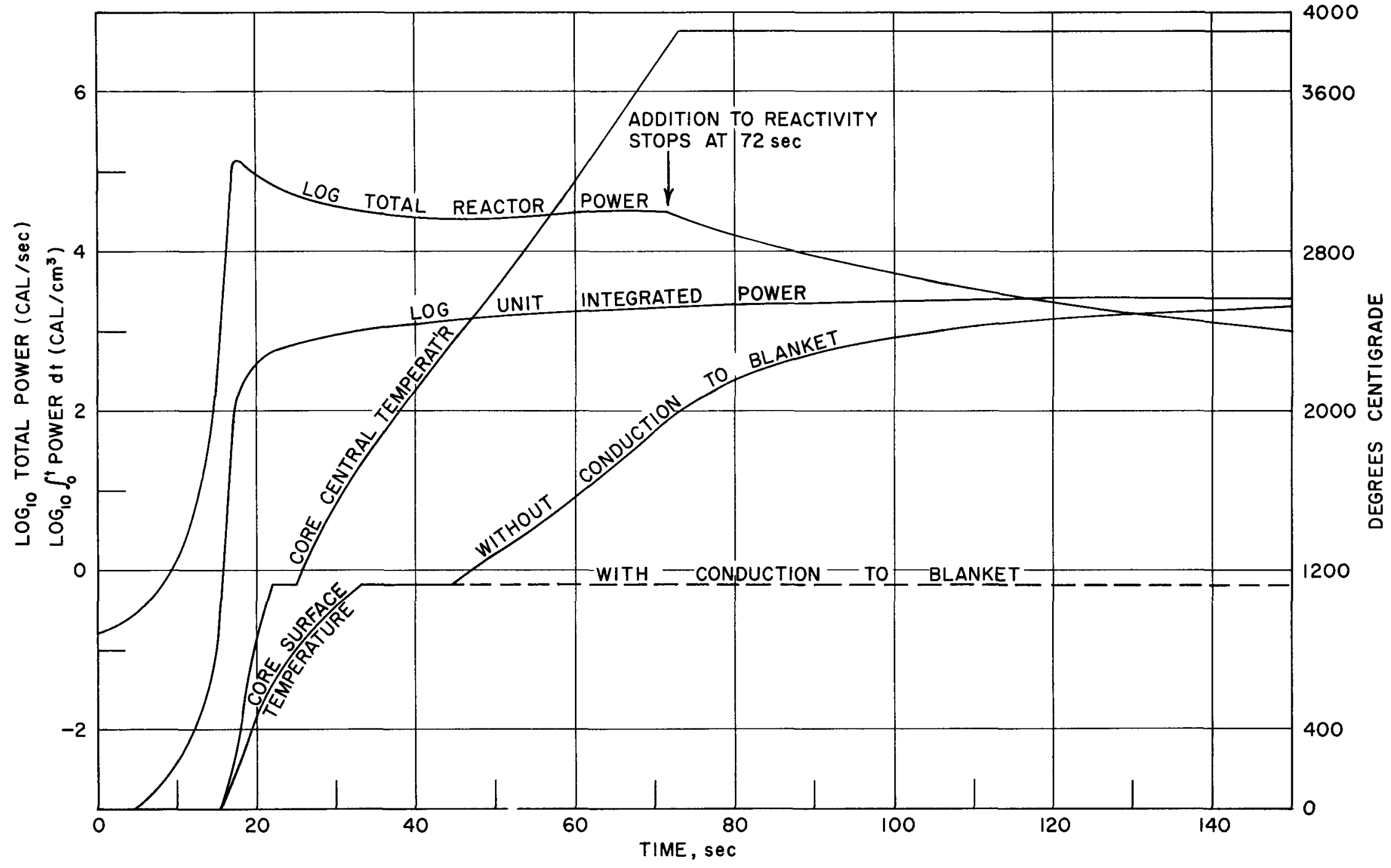

Predicted behavior of AFSR going critical 0.3 inch from fully as sembled position at a rate of $0.0004 \Delta \mathrm{k} / \mathrm{k}$ per second.

FIG. 21 


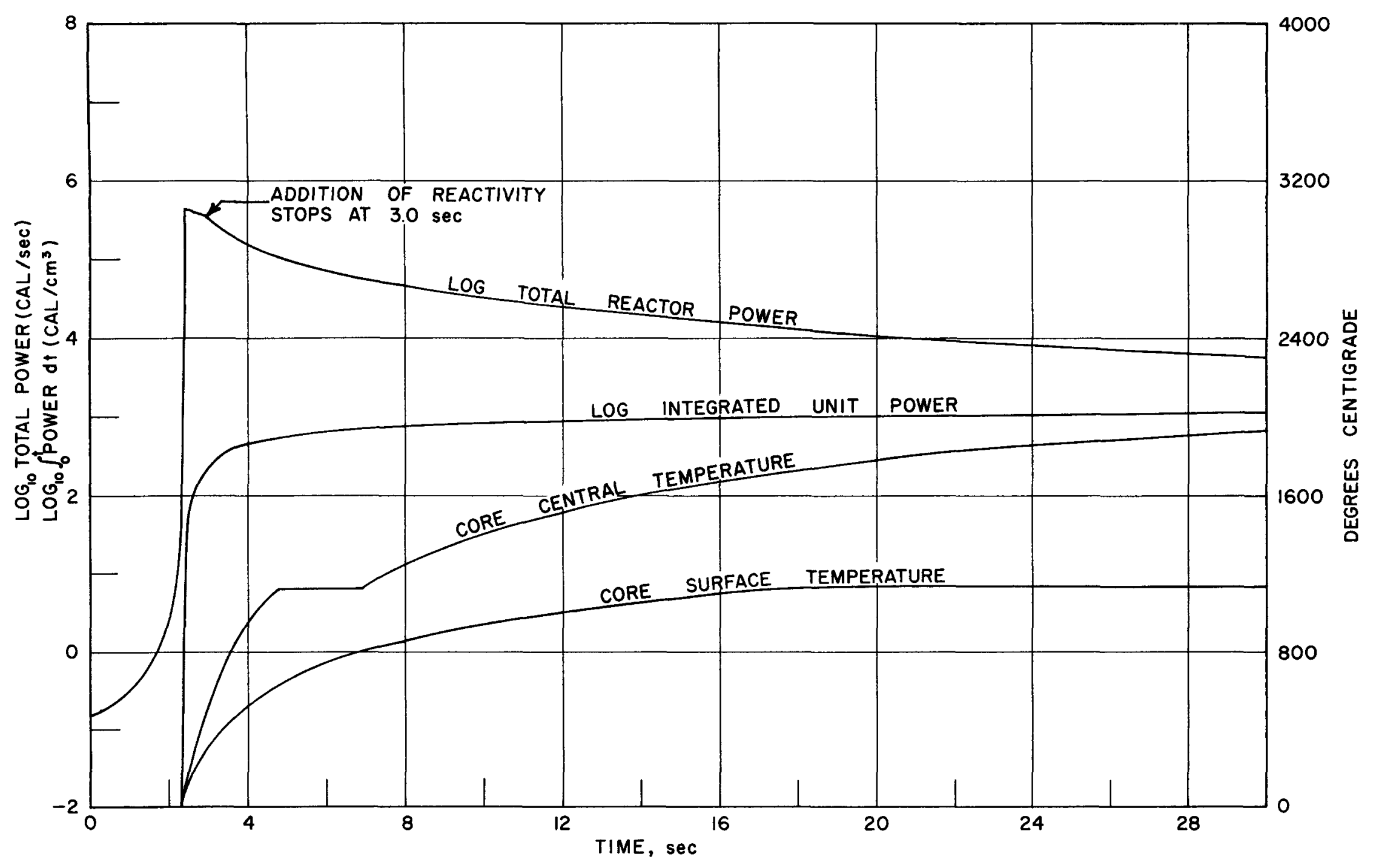

Predicted behavior of AFSR going critical 0.1 inch from fully as sembled position at a rate of $0.003 \Delta \mathrm{k} / \mathrm{k}$ per second.

FIG. 22 


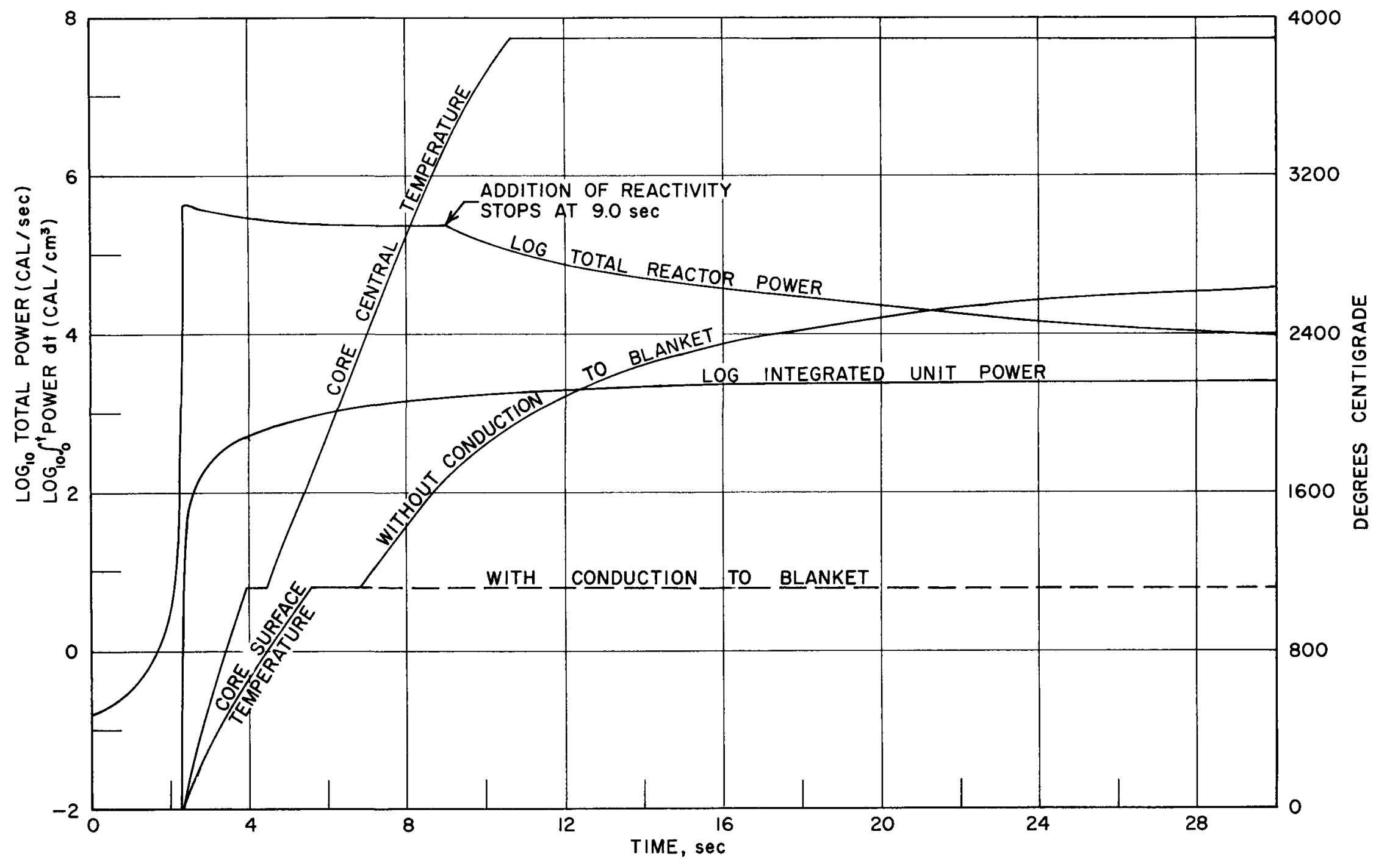

Predicted behavior of AFSR going critical 0.3 inch from fully as sembled position at a rate of $0.003 \Delta \mathrm{k} / \mathrm{k}$ per second.

FIG. 23 


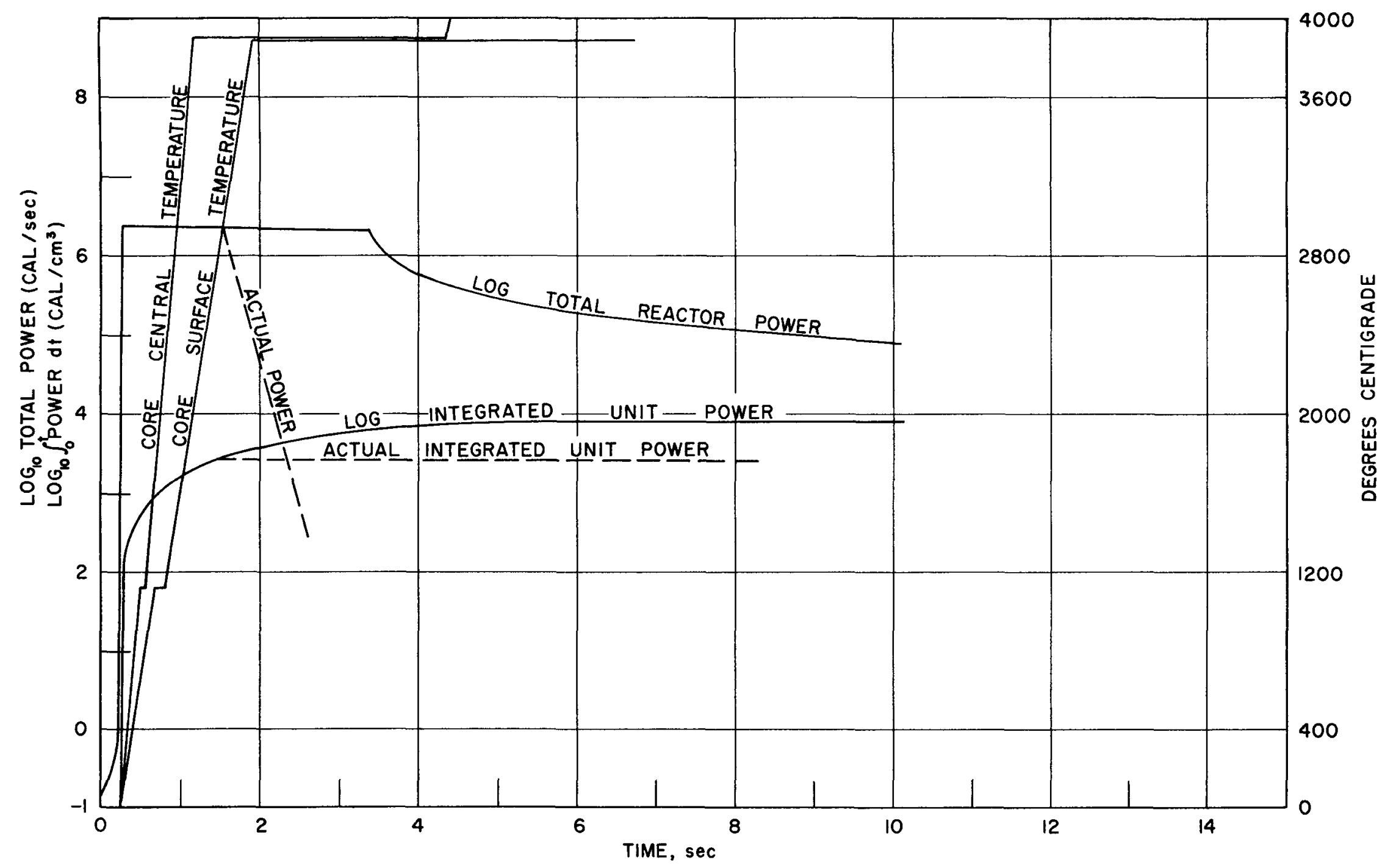

Predicted behavior of AFSR going critical one inch from fully assembled position at a rate of $0.03 \Delta \mathrm{k} / \mathrm{k}$ per second.

FIG. 24 